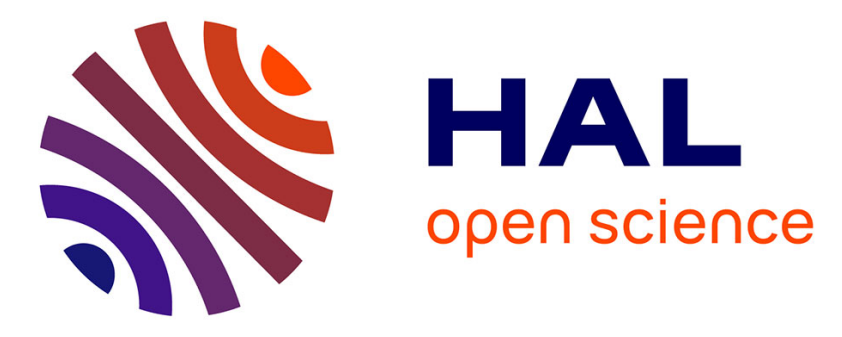

\title{
Production of Sc medical radioisotopes with proton and deuteron beams
}

Mateusz Sitarz, Katarzyna Szkliniarz, Jerzy Jastrzębski, Jaroslaw Choiński, Arnaud Guertin, Ferid Haddad, Andrzej Jakubowski, Kamil Kapinos, Maciej Kisieliński, Agnieszka Majkowska, et al.

\section{To cite this version:}

Mateusz Sitarz, Katarzyna Szkliniarz, Jerzy Jastrzębski, Jaroslaw Choiński, Arnaud Guertin, et al.. Production of Sc medical radioisotopes with proton and deuteron beams. Applied Radiation and Isotopes, 2018, 142, pp.104-112. 10.1016/j.apradiso.2018.09.025 . in2p3-01951123

\section{HAL Id: in2p3-01951123 \\ https://hal.in2p3.fr/in2p3-01951123}

Submitted on 26 Jan 2021

HAL is a multi-disciplinary open access archive for the deposit and dissemination of scientific research documents, whether they are published or not. The documents may come from teaching and research institutions in France or abroad, or from public or private research centers.
L'archive ouverte pluridisciplinaire HAL, est destinée au dépôt et à la diffusion de documents scientifiques de niveau recherche, publiés ou non, émanant des établissements d'enseignement et de recherche français ou étrangers, des laboratoires publics ou privés. 


\title{
ARI $2 \quad 08.07 .20$
}

\section{Production of Sc medical radioisotopes with proton and deuteron beams}

\author{
Mateusz Sitarz ${ }^{(1,2,3)}$, Katarzyna Szkliniarz ${ }^{(4)}$, Jerzy Jastrzębski ${ }^{(1, *)}$, \\ Jarosław Choiński ${ }^{(1)}$, Arnaud Guertin ${ }^{(5)}$, Ferid Haddad ${ }^{(3,5)}$, Andrzej Jakubowski ${ }^{(1)}$, \\ Kamil Kapinos $^{(1,2)}$, Maciej Kisieliński ${ }^{(1)}$, Agnieszka Majkowska ${ }^{(6)}$, \\ Etienne Nigron $^{(5)}$, Malihe Rostampour ${ }^{(6,7)}$, Anna Stolarz ${ }^{(1)}$, \\ Agnieszka Trzcińska ${ }^{(1)}$, Rafał Walczak ${ }^{(6)}$, Jolanta Wojtkowska ${ }^{(8)}$, Wiktor Zipper ${ }^{(4)}$, \\ Aleksander Bilewicz ${ }^{(6)}$
}

1) Heavy Ion Laboratory, University of Warsaw, 02-093 Warszawa, Poland

2) Faculty of Physics, University of Warsaw, 02-093 Warszawa, Poland

3) GIP ARRONAX, France

4) Institute of Physics, Department of Nuclear Physics and its Applications, University of Silesia, 41-500 Chorzów, Poland

5) SUBATECH, CNRS/IN2P3, IMT Atlantique, Université de Nantes, France

6) Institute of Nuclear Chemistry and Technology, 03-195 Warszawa, Poland

7) Department of Physics, Arak University, 38156 Arak, Iran

8) National Centre for Nuclear Research, 05-400 Otwock, Świerk, Poland

*Corresponding author: jastj@slcj.uw.edu.pl

KEYWORDS:

- proton and deuteron beams

- ${ }^{43,44,47}$ Sc radioisotopes

- radioisotope production

- Thick Target Yield

- generated impurities level 


\section{Highlights}

- The prospective medical scandium radioisotopes, ${ }^{43} \mathrm{Sc},{ }^{44 \mathrm{~g}} \mathrm{Sc},{ }^{44 \mathrm{~m}} \mathrm{Sc}$ and ${ }^{47} \mathrm{Sc}$ were produced using proton and deuteron beams.

- Isotopically enriched and natural targets of $\mathrm{CaCO}_{3}$ and $\mathrm{TiO}_{2}$ were used.

- The Thick Target Yields (TTY) and generated radioactive impurities were determined for a proton energy range of $28-2 \mathrm{MeV}$.

- Using a proton beam and the most enriched target isotopes the highest determined TTY were about 400, 800 and $60 \mathrm{MBq} / \mu \mathrm{Ah}$ for ${ }^{43} \mathrm{Sc},{ }^{44 \mathrm{~g}} \mathrm{Sc}$ and ${ }^{47}$ Sc,respectively. 


\section{ABSTRACT}

Proton and deuteron beams extracted from the PETtrace medical cyclotron at the Radiopharmaceuticals Production and Research Centre in the University of Warsaw, Heavy Ion Laboratory, $28 \mathrm{MeV}$ protons from the C30 cyclotron at the National Centre for Nuclear Research, Świerk, near Warsaw and $33 \mathrm{MeV}$ protons from the Arronax accelerator, Nantes were used to produce and investigate the medically interesting Sc radioisotopes. Both natural and isotopically enriched $\mathrm{CaCO}_{3}$ targets and highly enriched ${ }^{48} \mathrm{TiO}_{2}$ targets were used. The production efficiency and isotopic purity were determined and are reported here for the highest commercially available enrichments of the target material. The Thick Target Yield, Activities at the End of Bombardment (EOB) and the relative activities of produced impurities at EOB are reported for ${ }^{43} \mathrm{Sc},{ }^{44 \mathrm{~g}} \mathrm{Sc},{ }^{44 \mathrm{~m}} \mathrm{Sc}$ and ${ }^{47} \mathrm{Sc}$ produced with particle energies below $30 \mathrm{MeV}$.

\section{INTRODUCTION}

In a recent publication (Szkliniarz et al., 2016) we presented information on the production efficiency and the isotopic purity of positron emitting Sc radioisotopes $\left({ }^{43} \mathrm{Sc},{ }^{44 \mathrm{~g}} \mathrm{Sc}\right.$ and $\left.{ }^{44 \mathrm{~m}} \mathrm{Sc}\right)$ formed using an alpha particle beam of energy up to $30 \mathrm{MeV}$. We also presented there in detail the motivation and history of the investigation of the positron emitters ${ }^{43} \mathrm{Sc}$ and ${ }^{44} \mathrm{Sc}$. In the present paper we extend this study to two other possible production routes using a proton and deuteron beams. We also extend these studies to the prospective therapeutic ${ }^{47} \mathrm{Sc}$ radioisotope which may be formed using a proton beam. The production efficiency, isotopic purity and possible medical applications of Sc radioisotopes were previously studied in a number of works using proton (Krajewski et al., 2012, 2013; Severin et al., 2012; Müller et al., 2013; 2014; Hoehr et al., 2014; Hernandez et al., 2014; van der Meulen et al., 2015; Valdovinos et al., 2015; Singh et al. 2015, Domnanich et al. 2016a, 2016b, 2017a, 2017b) deuteron (Kuhn et al., 2013; Huclier-Markai et al., 2014; Alliot et al., 2015a, 2015b; Duchemin et al., 2015) and alpha particle beams (Kupsch and Könnecke, 1988; Kuhn et al. 2013; Coenen et al., 2014; Nagatsu et al., 2015; Walczak et al., 2015; Szkliniarz et al., 2015, 2016).

The ${ }^{43} \mathrm{Sc}$ and ${ }^{44} \mathrm{Sc}$ radioisotopes, thanks to their relatively long half-lives (3.89 $\mathrm{h}$ and $3.97 \mathrm{~h}$, respectively), may constitute an attractive alternative in Positron Emission Tomography to the currently employed ${ }^{18} \mathrm{~F}$ with a half-life of only $110 \mathrm{~min}$. In particular, in spite of poorer positron tomography resolution (Bunka et al., 2016) with these radioisotopes, their production using a single facility and subsequent distribution to hospitals not possessing a cyclotron and/or radiopharmaceutical synthesis equipment may be attractive. Also, F and Sc have completely different chemical reaction mechanisms which plays a key role in the preparation of different radiopharmaceuticals. 
The ${ }^{44 g} \mathrm{Sc}$ radioisotope has other properties making it more versatile than the classic ${ }^{18} \mathrm{~F}$. Firstly, it decays in large proportion via an excited state at 1157 $\mathrm{keV}$. The gamma line following the $99 \%$ positron emission feeding this state was suggested as an ideal coincidence partner to the two $511 \mathrm{keV}$ annihilation quanta in the so-called three-photon PET technique (Mausner et al., 1998; Grignon et al., 2007; Thirlof et al., 2015) which is expected to improve substantially the energy resolution originating from the finite range of the annihilating positrons. A decrease in the patient dose is also expected employing this technique (Lang et al., 2013).

${ }^{44} \mathrm{Sc}$ is also particularly interesting due to an isomeric state, $271 \mathrm{keV}$ above its ground state, decaying via an E4 transition to the ground state with a half-life of $2.4 \mathrm{~d}$. The exploitation of this decay cascade was recently proposed (HuclierMarkai et al., 2014; Alliot et al., 2015a, 2015b; Duchemin et al., 2015) to form an in vivo ${ }^{44 \mathrm{~m}} \mathrm{Sc} /{ }^{44 g} \mathrm{Sc}$ generator providing an internal positron source for many hours of the ${ }^{44 \mathrm{~m}} \mathrm{Sc}$ half-life. The ${ }^{44} \mathrm{Ca}(\mathrm{d}, 2 \mathrm{n})^{44 \mathrm{~m}, \mathrm{~g}} \mathrm{Sc}$ reaction was used in this series of experiments. The deuteron reaction on ${ }^{43} \mathrm{CaCO}_{3}$ was also recently reported (Bilewicz et al., 2016) as leading to the ${ }^{43} \mathrm{Sc}$ diagnostic radioisotope.

Besides the Sc positron emitters, prospective imaging radioisotopes-, the $\beta^{-}$ decaying ${ }^{47} \mathrm{Sc}$ radioisotope $\left(\mathrm{T}_{1 / 2}=3.35 \mathrm{~d}\right)$ is a candidate for employment as a low energy electron emitting therapeutic agent, constituting with one of the lighter Sc positron emitters an ideal theranostic pair. Its suggested fast or slow neutron production routes were investigated in a number of references (Kolsky et al., 1998; Mausner et al., 1998; Majkowska-Pilip and Bilewicz, 2011; Bartoś et al., 2012; Połosak et al., 2013; Müller et al., 2014; Domnanich et al., 2017) together with $(\gamma, p)$ reactions (Habs and Koester, 2011; Mamtimin et al., 2015; Rotsch et al. 2018). Research into a production method and radiopharmaceutical preparations based on this radioisotope was recently proposed within the IAEA Coordinated Research Project (CRP) (IAEA, 2015). Its accelerator production was discussed in this research project and also recently announced (Bilewicz et al., 2016; Bilewicz, 2016). Quite recently it was also studied by some of us (Misiak et al., 2017) using the $60 \mathrm{MeV}$ proton cyclotron in Kraków with a natural $\mathrm{CaCO}_{3}$ target. In the present, independent investigation the $28 \mathrm{MeV}$ proton beam from the cyclotron at NCNR, Świerk was used to irradiate natural as well as isotopically enriched ${ }^{48} \mathrm{CaCO}_{3}$ targets and a ${ }^{48} \mathrm{TiO}_{2}$ target. Finally, for verification purposes natural $\mathrm{CaCO}_{3}$ and natural $\mathrm{TiO}_{2}$ targets were irradiated with the lowest $(33 \mathrm{MeV})$ available energy energy from the Arronax cyclotron.

After the publication of the alpha particle routes for the formation of the two lightest Sc radioisotopes, in the present paper we investigate their production efficiency using proton and deuteron beams. However, we demonstrate that in order to achieve the best efficiency or isotopic purity the necessary energy of these projectiles in some cases should be above the energies available from most popular medical accelerators. In the case of the therapeutic ${ }^{47} \mathrm{Sc}$ we also compare 
the production efficiency and radioisotopic purity of this isotope formed via the proton and alpha particle routes.

The experimental data gathered using proton and deuteron beams are compared with the evaporation code EMPIRE and the TENDL library, based on TALYS evaporation model calculations.

Our experimental determinations of the Thick Target Yield (Krasnov, 1974) of ${ }^{43} \mathrm{Sc}$ and ${ }^{44 \mathrm{~g}} \mathrm{Sc}$ are also compared with the values calculated using the experimental cross-section data from two very recently published papers dealing with the determination of the cross-section for the production of positron emitting Sc radioisotopes by proton induced reactions on Ca targets (Carzaniga et al., 2017; Alabyad et al., 2018).

Finally, a review paper dealing, among others, with the status of the production routes and theranostic applications of medical Sc radioisotopes appeared very recently (Müller et al., 2018). Some questions, raised in this review are answered in the present publication.

\section{MATERIALS AND METHODS}

\subsection{The accelerators employed}

The target irradiations with protons were performed using three cyclotrons: a GE PETtrace p/d machine with a nominal energy of $16.5 \mathrm{MeV}$ (p) and $8.4 \mathrm{MeV}$ (d), a homemade C30 proton cyclotron (Sura et al., 1981; Marti ed. 2001) and for some control measurements the ARRONAX machine (Poirier et al., 2011). The first cyclotron is operated at the Radiopharmaceuticals Production and Research Centre put into operation by the Heavy Ion Laboratory, University of Warsaw a few years ago (Choiński et al., 2014). This cyclotron was recently equipped with an external beam line for solid sample irradiations, also allowing a good cooling conditions for these samples (Choiński et al., 2015). During the experiments described here the maximum proton energy impinging on the irradiated samples was determined by calculating the beam current as a function of the beam energy for a few monitor reactions, the cross-sections of which were taken from the most recent IAEA compilation (IAEA, 2017). The proton energy was assumed to correspond to the minimum value of the standard deviation between the calculated beam currents. The upper part of Fig. 1 presents an example of such a beam energy determination. The cyclotron energy can also be determined from the saturation activity ratio of the monitor reactions, as proposed by the Jülich group (Piel et al., 1992; Spellerberg et al., 2015). This is presented in the lower part of Fig. 1, taking into account all the sensitive saturation activity ratios of radioisotopes produced in the monitor foils employed. The adopted beam energy 
irradiating the investigated $\mathrm{CaCO}_{3}$ samples in the PETtrace external beam line was assessed as $15.2 \pm 0.1 \mathrm{MeV}$ (15.3 MeV- $1 / 2$ the energy degradation in the monitor foils). The maximum deuteron energy was correspondingly assumed to be $6.8 \mathrm{MeV}$. The maximum C30 proton energy was determined using the TOF method as equal to $28.0 \pm 0.5 \mathrm{MeV}$ and the ARRONAX machine proton energy was $33.0 \pm 0.5 \mathrm{MeV}$ as given by the producer and confirmed by the saturation activity ratio determination.

\subsection{Calcium and Titanium targets for proton and/or deuteron irradiation}

The majority of the studies on the production of Sc radioisotopes have been performed using calcium carbonate as target material. The ARRONAX group (Alliot et al., 2015b) used a thick target of $96.9 \%$ enriched ${ }^{44} \mathrm{CaCO}_{3}$ for production of ${ }^{44 \mathrm{~m}} \mathrm{Sc} /{ }^{449} \mathrm{Sc}$ in vivo positron generator with a deuteron beam. Similar studies of the production (with protons) and investigation of the ${ }^{44 g} \mathrm{Sc}$ radioisotope employed a thin enriched ${ }^{44} \mathrm{CaCO}_{3}$ target (Krajewski et al., 2012, 2013; Müller et al., 2014; van der Meulen et al., 2015). Quite recently the-PSI group (Domnanich et al., 2016) employed a thick target composed of the enriched Ca or Ti material backed by graphite to produce ${ }^{43} \mathrm{Sc}$. Pure metallic targets (natural thick target Wisconsin-Madison group (Severin et al., 2012; Hernandez et al., 2014; Valdovinos et al., 2015) or water target (water solution of natural calcium nitrate Vancouver group (Hoehr et al., 2014) have also been used for the production of ${ }^{44 \mathrm{~g} S c}$.

In the present studies of the reaction characteristics - as a function of projectile energy we used pellet targets designed as a homogenous mixture of the enriched target material, $\mathrm{CaCO}_{3}$ or $\mathrm{TiO}_{2}$, with graphite (Stolarz et al., 2018). The content of the enriched material in the mixture varied from 10 to $25 \%$ for $\mathrm{CaCO}_{3}$ and for $\mathrm{TiO}_{2}$ it was $20 \%$.

This method allows the production of thin as well as thick targets with low content of enriched material, while preserving the thickness of the target, ensuring the required decrease in the projectile energy. In a number of irradiations, determining the reaction yield natural $\mathrm{CaCO}_{3}$ targets, prepared in a similar way were also used.

Thin foils beam monitors made of nat. $\mathrm{Cu}, \mathrm{Ni}$ or $\mathrm{Ti}$ were added to each target. The thicknesses of the target and aluminium foil acting as energy degrader corresponded to the desired reaction cross-section range in the target material. 


\subsection{Data acquisition and evaluations}

The data acquisition systems and evaluations methods were identical to those previously described for alpha particle induced reactions (Szkliniarz et al., 2016). For the sake of completeness, they are briefly summarized below.The gamma ray spectra of the irradiated samples were collected using two HPGe counters (EG\&G ORTEC, model: GEM, HPGe $70.1 \mathrm{~mm}$ x $69.8 \mathrm{~mm}, 60 \%$ efficiency and CANBERRA, model: BE2825, thickness: $25.5 \mathrm{~mm}$, active area: $2800 \mathrm{~mm}^{2}$, with $0.6 \mathrm{~mm}$ thick Carbon Epoxy window). Shortly after irradiation the samples were placed at approximately $1 \mathrm{~m}$ distance from the detector. Later they were placed inside $10 \mathrm{~cm}$ thick $\mathrm{Pb}$ shielding (selected for its low background). A supplementary $\mathrm{Sn}-\mathrm{Cu}$ inner shielding (2.5 $\mathrm{mm}$ thickness of $\mathrm{Sn}$ and $0.5 \mathrm{~mm}$ thickness of $\mathrm{Cu}$ ) eliminated a large part (around 97\%) of the $\mathrm{Pb}$ fluorescence X-ray peaks caused by the sample radiation. Data were collected using the TUKAN8k/National Centre for Nuclear Research system. The gammaray spectra were analyzed using the TUKAN8k/National Centre for Nuclear Research software. The samples irradiated using the C30 cyclotron in Świerk were first measured using a HPGe EG\&G ORTEC vertical detector, model: GMX-25190-p, $56.8 \mathrm{~mm}$ x $70.0 \mathrm{~mm}$ with a $0.5 \mathrm{~mm}$ thick Be window and analyzed using Gamma Acquisition \& Analysis V1.4, Copyright 1999 By Canberra Industries. They were transported to the HIL counting system later in the day of irradiation and their subsequent decay was also followed. The samples irradiated using the ARRONAX cyclotron were measured using a HPGe CANBERRA detector with efficiency $20 \%$ at $1.33 \mathrm{MeV}$ and analyzed using FitzPeaks software.

Typical detector dead time during the measurements was below $10 \%$. The energy calibrations and absolute efficiencies of the HPGe detectors were determined using calibrated ${ }^{133} \mathrm{Ba},{ }^{137} \mathrm{Cs},{ }^{152} \mathrm{Eu}$ and ${ }^{241} \mathrm{Am}$ sources (with an uncertainty in their activity below 3\%).

After the series of gamma-ray spectra measurements for each sample the half-lives of the observed lines were determined and compared with data from the literature. Using their observed activities $A(T)$ at measuring time $T$ the radioisotope activity produced at the End of Bombardment $\left(\mathrm{A}_{\mathrm{EOB}}\right)$ was calculated. Similarly, following the prescription of Ref. (Krasnov, 1974) the experimental Thick Target Yields (in MBq/ $\mu \mathrm{Ah}$ ) were calculated from the formula:

$$
T T Y_{\text {exp }}=\lambda A \exp (\lambda T) /\{I(1-\exp (-\lambda t))\},
$$

where $\lambda$ is the decay constant of the product and $t$ is the irradiation time. These values were compared with the theoretical Thick Target Yields, $\mathrm{TTY}_{\sigma}$, from the formula (1) of Ref. (Szkliniarz et al., 2016) using the calculated cross-section values. The cross-sections of the studied reactions were obtained using the EMPIRE (Herman et al., 2007) evaporation code and the TENDL cross-section 
library (Koning and Rochman, 2012). The default option was used for the model parameters. In Fig. 2 the calculated cross-sections of the proton and deuteron induced reactions on ${ }^{42,43,44} \mathrm{Ca}$ isotopes as obtained with the EMPIRE code are shown. (The TENDL library gives very similar results with the exception of the deuteron induced reactions on a ${ }^{42} \mathrm{Ca}$ target, see below). Fig. 3 shows the crosssections of the Sc isotopes produced on the ${ }^{48} \mathrm{Ca}$ target calculated with the same code: the $(p, 2 n)$ reaction leading to ${ }^{47} \mathrm{Sc}$ and $(\mathrm{p}, \mathrm{n})$ and $(\mathrm{p}, 3 \mathrm{n})$ to the produced impurities. Finally, in Fig. 4 the cross-sections of the proton induced reactions on a ${ }^{48} \mathrm{Ti}$ target are shown. The theoretical $\mathrm{TTY}_{\text {th }}$ are calculated using the crosssections for incident energies from the particle bombarding energy impinging on the target down to the point when the cross-section becomes zero. Target Yield, TY are used, instead of the Thick Target Yield for cases when the target thickness is smaller than the projectile range with non-zero reaction cross-section. The experimental $\mathrm{A}_{\mathrm{EOB}}$, Thick Target Yields (TTY) or Target Yields (TY), as determined for the investigated radioisotopes are presented in Tables 3, 4 and 6.

\section{RESULTS AND DISCUSSION}

\subsection{Production of ${ }^{43}$ Sc radioisotope}

The production of ${ }^{43} \mathrm{Sc}$ using protons at energies available from medical accelerators was most recently investigated by the Bern-PSI group (Domnanich et al., 2016a, 2017). The ${ }^{43} \mathrm{Ca}(\mathrm{p}, \mathrm{n})^{43} \mathrm{Sc}$ and ${ }^{46} \mathrm{Ti}(\mathrm{p}, \alpha)^{43} \mathrm{Sc}$ reactions were used.

In the present work two ways of producing ${ }^{43} \mathrm{Sc}$ were investigated: following our previous communication (Bilewicz et al., 2016) the (d,n) reaction on a ${ }^{42} \mathrm{CaCO}_{3}$ target and the $(\mathrm{p}, \mathrm{n})$ reaction on a ${ }^{43} \mathrm{CaCO}_{3}$ target. The Thick Target Yields for various proton bombarding energies are presented in Table 3 and for deuterons in Table 4. The EOB activities and produced impurities for 15.2-2.2 $\mathrm{MeV}$ proton energy and 6.8-0 MeV deuteron energy are given in Table 5. The Thick Target Yield data of both reactions are compared to the theoretical values in Fig. 5.

From Figs. 2 and 5 it is evident that deuterons with energies of around 7 $\mathrm{MeV}$ produce only half of the possible ${ }^{43} \mathrm{Sc}$ activity in this reaction. A deuteron energy of $15 \mathrm{MeV}$, only available from cyclotrons with $30 \mathrm{MeV}$ proton beams would double the ${ }^{43} \mathrm{Sc}$ production yield. The $(\mathrm{p}, \mathrm{n})$ reaction on presently available ${ }^{43} \mathrm{CaCO}_{3}$ targets (enriched to $90 \%$ with $4.4 \%{ }^{44} \mathrm{Ca}$ content) gives a much higher TTY value but with about $11 \%{ }^{44}$ Sc impurity.

We have previously shown (Szkliniarz et al., 2016) that if an alpha particle beam of energy around and above $20 \mathrm{MeV}$ is available, the formation of very pure 
${ }^{43} \mathrm{Sc}$ radioisotope using an extremely cheap natural $\mathrm{CaCO}_{3}$ target may well be the most preferred production method, even avoiding the target recovery process.

\subsection{Production of ${ }^{44 g} S c$ and ${ }^{44 m} S c$ radioisotopes}

The production and medical applications of the two ${ }^{44} \mathrm{Sc}$ isomers were previously investigated in a number of works indicated above. In our irradiations both natural as well as $94.8 \%$ isotopically enriched ${ }^{44} \mathrm{CaCO}_{3}$ were used.

Besides ${ }^{40} \mathrm{Ca}$ the most abundant calcium isotope in the natural material is ${ }^{44} \mathrm{Ca}(2.086 \%)$. Therefore as the irradiation of ${ }^{40} \mathrm{Ca}$ by protons produces only short lived products, the natural target can be used for the preliminary, research production of ${ }^{44} \mathrm{Sc}$. A number of such targets in $\mathrm{CaCO}_{3}$ form were irradiated with the PETtrace proton beam for research on preclinical application of Sc radioisotopes by teams collaborating in the realization of a Polish Funding Agency NCBiR grant (Bilewicz et al., 2018; Mikołajczak et al., 2018; Kilian et al., 2018). For the $15.2 \mathrm{MeV}$ proton energy, the TTY value obtained for ${ }^{44} \mathrm{Sc}$ was 17.2(6) $\mathrm{MBq} / \mu \mathrm{Ah}$, with $3 \%$ of the largest impurity of ${ }^{43} \mathrm{Sc}$. This value would be increased to about $47 \mathrm{MBq} / \mu \mathrm{Ah}$ if metallic targets were used.

The Thick Target Yields of ${ }^{44 \mathrm{~g}} \mathrm{Sc}$ and ${ }^{44 \mathrm{~m}} \mathrm{Sc}$ determined for various proton energies are shown in Table 3. The EOB activities and relative activities of contaminating radioisotopes produced in these samples for $15.2-2.2 \mathrm{MeV}$ proton energy are given in Table 5. In Fig. 6 the determined TTY values of ${ }^{44 g, m}$ Sc are compared with the calculated ones and in Fig. 7 the evolution with time of the relative intensities of Sc isotopes. In Fig. 6 the data of Refs. (Severin et al., 2012; Valdovinos et al., 2015) are also shown. In these references, natural Ca metallic targets were irradiated. Therefore, the absolute values of TTY from these references were converted to $\mathrm{CaCO}_{3}$ target equivalents, multiplying them by 0.36 to reflect the difference in target atomic mass and stopping power. After such a conversion, the metallic target data are about $40 \%$ lower than those obtained in our experiment and also as calculated using the evaporation model cross-section values. This discrepancy is due to the proton beam being wider than the hole in the aluminium ring on which the calcium was pressed in the Wisconsin experiments with the metallic targets (Valdovinos, 2017).

In Refs. (Huclier-Markai et al., 2014; Alliot et al., 2015a, 2015b; Duchemin et al., 2015) the feasibility of the formation of an in vivo ${ }^{44 \mathrm{~m}} \mathrm{Sc} /{ }^{44 \mathrm{~g}} \mathrm{Sc}$ generator based on a high spin ${ }^{44 \mathrm{~m}} \mathrm{Sc}$ isomer with a 2.4 days half-life, decaying to the $3.97 \mathrm{~h}$ ${ }^{44 g} \mathrm{Sc}$ by a $271 \mathrm{keV}$ (E4) transition was investigated. Irradiation of ${ }^{44} \mathrm{Ca}$ by a 16 $\mathrm{MeV}$ deuteron beam was proposed. The use of this reaction was motivated by the higher ${ }^{44 \mathrm{~m}} \mathrm{Sc} /{ }^{449} \mathrm{Sc}$ cross-section ratio in comparison with proton induced reactions on the same target. Similarly, in our recent paper (Szkliniarz et al., 2016) we discussed the production of this isomeric state using a $29 \mathrm{MeV}$ alpha-particle beam and we demonstrated that for this projectile the measured ratio of the Thick 
Target Yield, TTY ${ }^{44 \mathrm{~m}} \mathrm{Sc} /{ }^{44 g d} \mathrm{Sc}$ is about 20 times larger than for $16 \mathrm{MeV}$ proton induced reactions and almost 5 times larger than for $15 \mathrm{MeV}$ deuteron induced reactions. Therefore, the production of ${ }^{44 \mathrm{~m}} \mathrm{Sc}$ using this irradiation route may be of interest. However, the much lower ${ }^{44 \mathrm{~m}} \mathrm{Sc}$ production cross-section for protons is compensated for by the substantially larger projectile range in a thicker target (smaller stopping power for this projectile). As a result, as demonstrated in our above mentioned reference, the Thick Target Yield and the EOB activity of ${ }^{44 \mathrm{~m}} \mathrm{Sc}$ is similar for protons as for deuterons and alpha particles, only with a much longer cooling time necessary for lighter projectiles. This is shown in Fig. 8 comparing the activity evolution of ${ }^{44 \mathrm{~m}, \mathrm{~g}} \mathrm{Sc}$ produced using beams of protons, deuterons and alpha-particles of the same intensity impinging on $100 \%$ enriched, thick $\mathrm{CaCO}_{3}$ targets. However, in considering the in vivo ${ }^{44 \mathrm{~m}} \mathrm{Sc} /{ }^{448} \mathrm{Sc}$ generator production two other aspects should be taken into account. Namely, the enriched ${ }^{42} \mathrm{Ca}$ target for the alpha-particle irradiations is about 4 times more expensive than the ${ }^{44} \mathrm{Ca}$ for deuteron and proton induced reactions. On the other hand, to generate the same ${ }^{44 \mathrm{~m}} \mathrm{Sc}$ thick target activity a much thicker target is necessary for deuterons and protons which compensates for the price difference but leads to a lower specific activity of samples prepared by deuteron bombardment and much lower by the proton route. All these aspects should be considered for large scale in vivo scandium generator production.

\subsection{Production of ${ }^{47}$ Sc radioisotope}

In the above mentioned first report of the Coordinated Research Project a number of possible nuclear reactions to produce ${ }^{47} \mathrm{Sc}$ with a $3.35 \mathrm{~d}$ half-life are listed. We have previously investigated (Szkliniarz, 2016) ${ }^{47}$ Sc production via the $(\alpha, n)$ reaction on $a^{\text {nat }} \mathrm{CaCO}_{3}$ target. Independently, shortly before our investigation ${ }^{47} \mathrm{Sc}$ production by an alpha particle beam was studied in a paper by a Japanese group (Minegishi et al., 2016) We have calculated using the natural target data measured at $20 \mathrm{MeV}$ alpha particle bombarding energy a TTY value of ${ }^{47}$ Sc equal to $1.0(1) \mathrm{MBq} / \mu \mathrm{Ah}$ for a highly enriched ${ }^{44} \mathrm{CaCO}_{3}$ target with a strong contamination of relatively short lived ${ }^{43} \mathrm{Sc}$ (about 28\%) and the dangerous long lived ${ }^{46} \mathrm{Sc}(1.3 \%$ at EOB after $12 \mathrm{~h}$ irradiation). Using the EMPIRE evaporation code, we estimated that rather pure ${ }^{47} \mathrm{Sc}$ can be formed at a bombarding energy of $16 \mathrm{MeV}$. At this energy, however, the calculated ${ }^{47} \mathrm{Sc}$ TTY value for $95 \%$ enrichment of ${ }^{44} \mathrm{CaCO}_{3}$ is only about $0.5 \mathrm{MBq} / \mu \mathrm{Ah}$, much below the possibilities for practical use of this production route with presently available alpha-particle beam intensities at the currently operating accelerators.

The proton route ${ }^{48} \mathrm{Ca}(\mathrm{p}, 2 \mathrm{n}){ }^{47} \mathrm{Sc}$ was recently investigated by some of us using the Kraków cyclotron, delivering a $60 \mathrm{MeV}$ proton beam (Misiak et al., 2017) irradiating a natural $\mathrm{CaCO}_{3}$ target. In the present, independent investigation the C30 cyclotron at Świerk and the Arronax machine were used, irradiating a 
$62.9 \%$ enriched ${ }^{48} \mathrm{CaCO}_{3}$ target and natural $\mathrm{CaCO}_{3}$ targets as well as a titanium dioxide target.

From Fig. 3 it is clear that only a small energy region may be available for this reaction without important production of impurities: the (p,n) reaction leads to the slightly shorter lived $44 \mathrm{~h}{ }^{48} \mathrm{Sc}$ whereas the (p,3n) reaction produces the much longer lived $84 \mathrm{~d}^{46} \mathrm{Sc}$. Both these impurities emit a number of high energy gamma lines and should be minimized or eliminated from the produced ${ }^{47} \mathrm{Sc}$.

In Fig. 9 the determined Thick Target Yield of ${ }^{47} \mathrm{Sc}$ by the $(\mathrm{p}, 2 \mathrm{n})$ reaction on a $97.1 \%{ }^{48} \mathrm{CaCO}_{3}$ target for different energies is shown and compared with TENDL library and EMPIRE evaporation code predictions. The presented data are deduced from experiments with proton energies of $15.2-2.2 \mathrm{MeV}, 22.8$ 17.1 $\mathrm{MeV}$ and $28.5-16.4 \mathrm{MeV}$. The analysis of the measured spectra indicates that only the 22.8-17.1 MeV proton energy range may be considered as appropriate. In Fig. 12 the evolution with time of Sc and Ca isotopes produced in a $97.1 \%{ }^{48} \mathrm{Ca}$ sample after a $8 \mathrm{~h}$ proton bombardment is presented. Although for this energy range the EOB activity of the long lived ${ }^{46} \mathrm{Sc}$ impurity is not observed the ${ }^{48} \mathrm{Sc}$ activity represents about $26 \%$ of the ${ }^{47} \mathrm{Sc}$ activity (Table 5 ). Assuming that $380 \mathrm{~h}$ cooling time is applied to the ${ }^{48} \mathrm{Ca}$ sample irradiated with a $1 \mu \mathrm{A}$ proton beam the observed gamma ray spectrum does not indicate other strong contaminant activities. At this time after EOB the ${ }^{47} \mathrm{Sc}$ activity is $26 \mathrm{MBq}$. Therefore, with a $100 \mu \mathrm{A}$ beam intensity the ${ }^{48} \mathrm{Ca}$ target should be irradiated for $10 \mathrm{~h}$ in order to obtain $3 \mathrm{GBq}$ of ${ }^{47} \mathrm{Sc}$ at $380 \mathrm{~h}$ after EOB with $1 \%$ of ${ }^{48} \mathrm{Sc}$ contamination. Assuming that there is no biological excretion i.e. that this $1 \%$ ${ }^{48} \mathrm{Sc}$ activity remains in the patient till complete decay, the received supplementary dose coming from ${ }^{48} \mathrm{Sc}$ activity would be about $54 \mathrm{mSv}$ (IAEA, 2011). Similarly, a cooling time of $120 \mathrm{~h}$ leads to $21 \mathrm{GBq}$ of ${ }^{47} \mathrm{Sc}$ with $10 \%$ of ${ }^{48} \mathrm{Sc}$. A fraction of $2 \mathrm{GBq}$ of ${ }^{47} \mathrm{Sc}$ extracted from it comes with a ${ }^{48} \mathrm{Sc}$ impurity that leads to $340 \mathrm{mSv}$ supplementary dose.

It is worth mentioning here that in Ref. (Misiak et al., 2017) for an energy range very similar to ours of $24.1-16.9 \mathrm{MeV}$ the contribution of ${ }^{48} \mathrm{Sc}$ was found to be more than a factor 1.4 lower than determined in the present work. The reason for this discrepancy, illustrated in Fig. 10, is unknown. The similar comparison for ${ }^{47}$ Ca production is showed on Fig. 11.

A relatively cheap ${ }^{48} \mathrm{Ti}$ target was used for the investigation of a second route suggested in the IAEA Report (IAEA, 2016) namely the ${ }^{48} \mathrm{Ti}(\mathrm{p}, 2 \mathrm{p})^{47} \mathrm{Sc}$ reaction. The calculated cross-sections for this reaction are presented in Fig. 4, together with the cross-sections of the generated impurities. The irradiation experiment was performed using the C30 cyclotron at Świerk, with $15 \mathrm{nA}$ of 27.7 $\mathrm{MeV}$ protons impinging on a thick ${ }^{48} \mathrm{TiO}_{2}$ target during about $5 \mathrm{~h}$ and verified by the irradiation of a natural $\mathrm{TiO}_{2}$ target with $28.0-18.3 \mathrm{MeV}$ protons during $20 \mathrm{~min}$ at the ARRONAX facility.

Table 6 shows the Thick Target Yield of ${ }^{47} \mathrm{Sc}$, the ${ }^{47} \mathrm{Sc}$ activity after $8 \mathrm{~h}$ of irradiation with a current of $1 \mu \mathrm{A}$ of a ${ }^{48} \mathrm{Ti}$ target. At EOB, the strongest impurity 
activity belongs to ${ }^{44 g} \mathrm{Sc}$, produced in seven reaction paths (Soppera, et al., 2012). It can be calculated that $40 \mathrm{~h}$ after EOB the ${ }^{44 \mathrm{~g}, \mathrm{~m}} \mathrm{Sc}$ activities each represent about $70 \%$ of the ${ }^{47} \mathrm{Sc}$ activity and could perhaps be used (after a slightly longer cooling time) within the same sample irradiation as diagnostic partners of ${ }^{47} \mathrm{Sc}$. However at this time the produced activity with a $100 \mu \mathrm{A}$ proton beam would be only 2 $\mathrm{GBq}$, with $0.03 \%$ contamination of the dangerous ${ }^{46} \mathrm{Sc}$ radioisotope.

\section{SUMMARY AND CONCLUSIONS}

The ${ }^{43} \mathrm{Sc}$ and ${ }^{44} \mathrm{Sc}$ medical radioisotopes previously investigated using alpha particle beams were produced in the present work with proton beams and ${ }^{43} \mathrm{Sc}$ also by deuteron beams. A third Sc isotope produced by protons was added to this investigation, namely the therapeutic ${ }^{47} \mathrm{Sc}$, a theranostic partner of the ${ }^{43} \mathrm{Sc}$ or ${ }^{44} \mathrm{Sc}$ positron emitters. The Thick Target Yield and the isotopic purity of the produced positron emitters were determined and compared with evaporation model predictions.

It was deduced that the most appealing route for the production of the ${ }^{43} \mathrm{Sc}$ radioisotope would be irradiation of natural $\mathrm{CaCO}_{3}$ or metallic Ca targets with an alpha-particle beam of energy around and above $20 \mathrm{MeV}$. Reasonable sample intensities and acceptable isotopic purity would be obtained in $15 \mathrm{MeV}$ deuteron induced reactions on isotopically enriched ${ }^{42} \mathrm{CaCO}_{3}$. The proton irradiation of ${ }^{43} \mathrm{CaCO}_{3}$, although with substantially higher efficiency than the deuteron route, leads to samples with about $10 \%$ of ${ }^{44} \mathrm{Sc}$ impurity with the presently available enrichments.

Substantial quantities of relatively pure (impurities equal to or below 3\%) ${ }^{44 g} \mathrm{Sc}$ can be produced using a $15 \mathrm{MeV}$ proton beam impinging on natural $\mathrm{CaCO}_{3}$ or metallic Ca targets. At this proton energy using an enriched ${ }^{44} \mathrm{CaCO}_{3}$ target the very high Thick Target Yield of about $800 \mathrm{MBq} / \mu \mathrm{Ah}$ was determined for the ground state of ${ }^{44} \mathrm{Sc}$. Although at this bombarding energy the TTY of ${ }^{44 \mathrm{~m}} \mathrm{Sc}$ is about 200 times lower, it was estimated that about $1 \mathrm{GBq}$ of this isomer without directly produced ground state activity can be obtained during 12 hours irradiation of a $100 \%$ enriched sample with $25 \mu \mathrm{A}$ proton beam current followed by $40 \mathrm{~h}$ cooling time.

There is growing interest in the accelerator production of the therapeutic ${ }^{47} \mathrm{Sc}$ radioisotope which may be considered as a theranostic partner of the above discussed Sc positron emitters. Although fast and slow neutron induced reactions were mainly used to date to produce substantial quantities of ${ }^{47} \mathrm{Sc}$, the cyclotron routes were also advocated in the ongoing Common Research Project (CRP) of the IAEA (IAEA, 2016). We have previously produced this radioisotope with an alpha-particle beam (Szkliniarz, 2016) but the determined TTY was too low to have practical applications with the presently available beam intensities. Two 
other reactions were investigated in the present work: ${ }^{48} \mathrm{Ca}(\mathrm{p}, 2 \mathrm{n}){ }^{47} \mathrm{Sc}$ and ${ }^{48} \mathrm{Ti}(\mathrm{p}, 2 \mathrm{p}){ }^{47} \mathrm{Sc}$. As is evident from the calculated cross section values, these reactions can only be used to obtain relatively pure ${ }^{47} \mathrm{Sc}$ over a small energy range. Selecting this range for the first reaction from 23 to $17 \mathrm{MeV}$ one obtains about $50 \mathrm{MBq} / \mu \mathrm{Ah}$ for the Target Yield. However, at EOB these irradiation conditions give a contaminating activity of ${ }^{48} \mathrm{Sc}$ of about $26 \%$ of the ${ }^{47} \mathrm{Sc}$. The yield is even lower for the second reaction investigated which also produces important impurities.

The experimental data obtained were compared with the evaporation code EMPIRE and the TENDL library, based on TALYS evaporation model calculations. The agreement between theoretical predictions and experimental data is with a few exceptions, rather good.

\section{ACKNOWLEDGEMENTS}

The authors warmly thank the PETtrace operation team for running a number of the beam hours necessary for the research described in this paper. Discussions with Krzysztof Ciupek, Nick Keeley and Ulli Koester, are appreciated. Part of this work was performed within the framework of the EU Horizon 2020 project RIA-ENSAR2 (654 002). This research was also partly supported by the Polish Funding Agency NCBiR grant No. DZP/PBS3/2319/2014. 


\section{REFERENCES}

Alabyad, M., Mohamed, G.V., Hassan, H.E., Takacs, S., Ditroi, F., 2018. Experimental measurement and theoretical calculations for proton, deuteron and $\alpha$-particle induced nuclear reactions on calcium: special relevance to the production of 43,44Sc. Journ. Radioan. Nucl. Chem. 316:119.

Alliot, C., Audouin, N., Barbet, J., Bonraisin, A.C., Bossé, V., Bourdeau, C., Bourgeois, M., Duchemin, C., Guertin, A., Haddad, F., Huclier-Markai, S., Kerdjoudj, R., Laizé, J., Métivier, V., Michel, N., Mokili, M., Pageau, M., Vidal, A., 2015a. Is there an interest to use deuteron beams to produce non-conventional radionuclides?. Reviews in Medicine 2, 31.

Alliot, C., Kerdjoudj, R., Michel, N., Haddad, F., Huclier-Markai, S., 2015b. Cyclotron production of high purity ${ }^{44 m, 44} \mathrm{Sc}$ with deuterons from ${ }^{44} \mathrm{CaCO}_{3}$ targets. Nucl. Med. Biol. 42, 524.

Bartoś, B., Majkowska, A., Kasperek, A., Krajewski, S., Bilewicz, A., 2012. New separation method of no-carrier-added ${ }^{47} \mathrm{Sc}$ from titanium targets. Radiochim. Acta 100, 457.

Bilewicz, A., 2016. New Cyclotron Method for ${ }^{47}$ Sc Production and Conjugation of ${ }^{47} \mathrm{Sc}$ to Monoclonal Antibodies. Accepted Research Project proposal. IAEA Research Contract No. 20488/R0.

Bilewicz, A., Walczak, R., Majkowska, A., Misiak, R., Choinski, J., Sitarz, M., Stolarz, A., Jastrzębski, J., 2016. Cyclotron production of theranostic pair ${ }^{43}$ Sc${ }^{47}$ Sc on calcium targets. Eur. J. Nucl. Med. Mol. Imaging 43 (Suppl 1): S135.

Bilewicz, A., et al. 2018. To be publ.

Bunka, M., Mueller, C., Vermeulen, C., Haller, S., Türler, A., Schibli, R., van der Meulen, N.P., 2016. Imaging quality of ${ }^{44} \mathrm{Sc}$ in comparison with five other PET radionuclides using Derenzo phantoms and preclinical PET. Appl. Radiat. Isot. 110, 129.

Carzaniga, T.S., Auger, M., Braccini, S., Bunka, M., Ereditato, A., Nesteruk, K.P., Scampoli, P., Türler, A., van der Meulen, N. 2017. Measurement of ${ }^{43}$ Sc and ${ }^{44} \mathrm{Sc}$ production cross-section with an $18 \mathrm{MeV}$ medical PET cyclotron, Appl. Radiat. Isot. 129, 96. 
Choiński, J., Jastrzębski, J., Kilian, K., Mazur, I., Napiorkowski, P.J., Pękal, A., Szczepaniak, D., 2014. The Radiopharmaceuticals Production and Research Centre established by the Heavy Ion Laboratory of the University of Warsaw. EPJ Web of Conferences 66, 10003.

Choiński, J., Bracha, T., Radomyski, B., Świątek, Ł., Antczak, M., Jakubowski, A., Jastrzębski, J., Kopik, R., Miszczak, J., Saeed Mohamed Nassar, O., Pietrzak, A., Stolarz, A., Tańczyk, R., 2015. Accelerator production of ${ }^{99 m}$ Tc-an external, well cooled, target holder for the PETtrace cyclotron. Annual Report HIL Warsaw.

Coenen, H.H., Kuhn, S., Spahn, I., 2014. Development of the non-standard PET radionuclides ${ }^{43,44 g}$ Sc and ${ }^{45}$ Ti. Nucl. Med. Biol. 41, 647.

Domnanich, K.A., Eichler, R., Müller, C., Jordi, S., Yakusheva, V., Braccini, S., Behe, M., Schibli, R., Türler, A., van der Meulen, N.P., 2017. Production and separation of 43Sc for radiopharmaceutical purposes. EJNMMI Radiopharmacy and Chemistry 2:14.

Domnanich, K.A., Müller, C., Benešová, M., Dressler, R., Haller, S., Köster, U., Ponsard, B., Schibli, R., Türler, A., van der Meulen, N.P., 2017. 47Sc as useful $\beta^{-}$ - emitter for the radiotheragnostic paradigm: a comparative study of feasible production routes. EJNMMI Radiopharmacy and Chemistry 2:5.

Domnanich, K.A., Müller, C., Farkas, R., Schmid R.M., Ponsard, B., Schibli, R., Türler, A., van der Meulen, N.P., 2016b. ${ }^{44}$ Sc for labeling of DOTA- and NODAGA-functionalized peptides: preclinical in vitro and in vivo investigations. EJNMMI Radiopharmacy and Chemistry 1:8.

Domnanich, K.A., Müller, C., Türler, A., van der Meulen, N.P., 2016a. ${ }^{43}$ Sc Production Development by Cyclotron Irradiation of ${ }^{43} \mathrm{Ca}$ and ${ }^{46} \mathrm{Ti}$. Radiotherapy \& Oncology 118, 1.

Duchemin, C., Guertin, A., Haddad, F., Michel, N., Métivier, V., 2015. Production of scandium-44m and scandium-44g with deuterons on calcium-44: cross-section measurements and production yield calculations. Phys. Med. Biol. $60,6847$.

Gagnon, K., Jensen, M., Thisgaard, H., Publicover, J., Lapi, S., McQuarrie, S.A., Ruth, T.J., 2011. A new and simple calibration-independent method for measuring the beam energy of a cyclotron. Appl. Radiat. Isot. 69(1), 247. 
Grignon, C., Barbet, J., Bardiès, M., Carlier, T., Chatal, J.F., Couturier, O., Cussonneau, J.P., Faivre, A., Ferrer, L., Girault, S., Haruyama, T., Le Ray, P., Luqiun, L., Lupone, S., Métivier, V., Morteau, E., Servagent, N., Thers, D., 2007. Nuclear medical imaging using $\beta+\gamma$ coincidence from ${ }^{44} \mathrm{Sc}$ radio-nuclide with liquid xenon as detection medium. Nucl. Instrum. Meth. A 571, 142.

Habs, D., Köster, U., 2011. Production of Medical Radioisotopes with High Specific Activity in Photonuclear Reactions with $\gamma$ Beams of High Intensity and Large Brillance. Appl. Phys. B. 103: 501.

Herman, M., Capote, R., Carlson, B.V., Obložinský, P., Sin, M., Trkov, A., Wienke, H., Zerkin, V., 2007. EMPIRE: Nuclear Reaction Model Code System for Data Evaluation. NDS 108, 2655.

Hernandez, R., Valdovinos, H.F., Yang, Y., Chakravarty, R., Hong, H., Barnhart, T.E., Cai, W., 2014. ${ }^{44}$ Sc: An Attractive Isotope for Peptide-Based PET Imaging. Mol. Pharmaceutics. 11, 2954.

Hoehr, C., Oehlke, E., Benard, F., Lee, C.J., Hou, X., Badesso, B., Ferguson, S., Miao, Q., Yang, H., Buckley, K., Hanemaayer, V., Zeisler, S., Ruth, T., Celler, A., Schaffer, P., 2014. ${ }^{44 g}$ Sc production using a water target on a $13 \mathrm{MeV}$ cyclotron. Nucl. Med. Biol. 41, 401.

Huclier-Markai, S., Kerdjoudj, R., Alliot, C., Bonraisin, A.C., Michel, N., Haddad, F., Barbet, J., 2014. Optimization of reaction conditions for the radiolabeling of DOTA and DOTA-peptide with ${ }^{44 \mathrm{~m} / 44} \mathrm{Sc}$ and experimental evidence of the feasibility of an in vivo PET generator. Nucl. Med. Biol. 41, e36.

IAEA, 2011. Radiation Protection and Safety of Radiation Sources: International Basic Safety Standards. IAEA Safety Standards Series No. GSR Part 3 (Interim Edition).

IAEA, 2015. Call for Coordinated Research Project "Therapeutic Radiopharmaceuticals Labelled with New Emerging Radionuclides $\left({ }^{67} \mathrm{Cu},{ }^{186} \mathrm{Re}\right.$, ${ }^{47}$ Sc)”. Vienna.

IAEA, 2016. Report on the $1^{\text {st }}$ Research Coordination Meeting on Therapeutic Radiopharmaceuticals Labelled with New Emerging Radionuclides $\left({ }^{67} \mathrm{Cu},{ }^{186} \mathrm{Re}\right.$, $\left.{ }^{47} \mathrm{Sc}\right)$. Vienna.

IAEA, 2017. Monitor reactions updated by S. Takacs, Aug. 2017 
https://www-nds.iaea.org/medical/monitor_reactions.html

Khandaker, M.U., Kim, K., Lee, M.W., Kim, K.S., Kim, G.N., Cho, Y.S., Lee, Y.O., 2009. Investigations of the natTi(p,x) 43,44m,44g,46,47,48Sc,48V nuclear processes up to $40 \mathrm{MeV}$. Appl. Radiat. Isot. 67, 1348.

Kilian, K., et al. 2018. To be publ.

Kolsky, K.L., Joshi, V., Mausner, L.F., Srivastava, S.C., 1998. Radiochemical purification of no-carrier-added scandium-47 for radioimmunotherapy. Appl. Radiat. Isot. 49, 1541.

Koning, A.J., Rochman, D., 2012. Modern Nuclear Data Evaluation with The TALYS Code System. NDS 113, 2841.

Krajewski, S., Cydzik, I., Abbas, K., Bulgheroni, A., Simonell, F., MajkowskaPilip, A., Bilewicz, A., 2018. Simple procedure of DOTATATE labelling with cyclotron produced ${ }^{44}$ Sc and ${ }^{43}$ Sc. Nucl. Med. Rev. 15, A27.

Krajewski, S., Cydzik, I., Abbas, K., Bulgheroni, A., Simonell, F., Holzwarth, U., Bilewicz, A., 2013. Cyclotron production of ${ }^{44}$ Sc for clinical application. Radiochim. Acta. 101, 333.

Krasnov, N.N., 1974. Thick target yield. Int. J. Appl. Radiat. Isot. 25, 223.

Kuhn, S., Spahn, I., Scholten, B., Hermanne, A., Coenen, H.H., 2013. Production of the medically interesting radioisotopes ${ }^{44,44 \mathrm{~m}} \mathrm{Sc}$ and their radioactive byproducts via deuteron and alpha-particle induced nuclear reactions on natural Ca and K. J. Label Compd. Radiopharm. 56, S232.

Kupsch, H., Könnecke, H.G., 1988. Verfahren zur Gewinnung von radionuklidisch reinem Scandium-43. Patentschrift DD 272726 A1. ISSN 04336461.

Lang, C., Habs, D., Parodi, K., Thirolf, P.G., 2013. Sub-millimeter nuclear medical imaging with reduced dose application in positron emission tomography using $\beta \gamma$ coincidences. JINST 9 P01008.

Lommel, B., Beusch, A., Hartmann, W., Hübner, A., Kindler, B., Steiner, J., Yakusheva, V., 2014. Reduction of isotopically enriched 50Ti-dioxide for the production of high-intensity heavy-ion beam. J. Radioanal. Nucl. Chem. 299, 977. 
Majkowska-Pilip, A., Bilewicz, A., 2011. Macrocyclic complexes of scandium radionuclides as precursors for diagnostic and therapeutic radiopharmaceuticals. J. Inorg. Biochem. 105(2), 313.

Mamtimin, M., Harmon, F., Starovoitova, V., 2015. Sc-47 production from titanium targets using electron linacs. Appl. Radiat. Isot. 102, 1.

Marti, F., (editor), 2001. Proceedings from Sixteenth International Conference: Cyclotrons and their applications. AIP Conference Proceedings vol. 600, 513.

Mausner, L.F., Kolsky, K.L., Joshi, V., Srivastava, S.C., 1998. Radionuclide development at BNL for nuclear medicine therapy. Appl. Radiat. Isot. 49, 285.

Mikołajczak, R., et al. To be publ.

Minegishi, K., Nagatsu, K., Fukada, M., Suzuki, H., Ohya, T., Zhang, M-R., 2016. Production of scandium-43 and -47 from a powdery calcium oxide target via the ${ }^{\text {nat } / 44} \mathrm{Ca}(\alpha, \mathrm{x})$-channel. App. Radiat. Isot. 116, 8.

Misiak, R., Walczak, R., Wąs, B., Bartyzel, M., Mietelski, J.W., Bilewicz, A., 2017. ${ }^{47}$ Sc production development by cyclotron irradiation of ${ }^{48} \mathrm{Ca}$, J. Radioanal. Nucl. Chem. 313, 429.

Müller, C., Bunka, M., Haller, S., Köster, U., Groehn, V., Bernhardt, P., van der Meulen, N.P., Türler, A., Schibli, R., 2014. Promising Prospects for ${ }^{44}$ Sc- $/{ }^{47}$ ScBased Theragnostics: Application of ${ }^{47} \mathrm{Sc}$ for Radionuclide Tumor Therapy in Mice. J. Nucl. Med. 55, 1658.

Müller, C., Bunka, M., Reber, J., Fischer, C., Zhernosekov, K., Tueler, A., Schibi, R., 2013. Promises of cyclotron-produced ${ }^{44} \mathrm{Sc}$ as a diagnostic match for trivalent $\beta$-emitters: in vitro and in vivo study of a ${ }^{44}$ Sc-DOTA-folate conjugate. J. Nucl. Med. 54, 2168.

Müller, C., Domnanich, K.A., Umbricht, C.A., van der Meulen, N.P., 2018. Scandium and terbium radionuclides for radiotheranostics: current state of development towards clinical application. Br. J. Radiol. 91: 20180074.

Nagatsu, K., Minegishi, K., Zhang, M-R., 2015. A study on remote production of ${ }^{43} \mathrm{Sc}$ from ${ }^{\text {nat }} \mathrm{CaO}$ target via the ${ }^{\text {nat }} \mathrm{Ca}(\alpha, \mathrm{x})$-reaction. Labelled Compd. Radiopharm. 58 (S1), 388. 
Piel, H., Qaim, S.M., Stöcklin, G., 1992. Excitation Functions of (p,xn)-Reactions on natNi and Highly Enriched 62Ni: Possibility of Production of Medically Important Radioisotope 62Cu at a Small Cyclotron. Radiochim. Acta. 57, 1.

Poirier, F., Girault, F., Auduc, S., Huet, C., Mace, E., Delvaux, J.I., Haddad, F., 2011. The C70 Arronax and beam lines status. Proc. of IPAC2011, San Sebastián, Spain.

Połosak, M., Piotrowska, A., Krajewski, S., Bilewicz, A., 2013. Stability of ${ }^{47}$ Sccomplexes with acyclic polyamino-polycarboxylate ligands. J. Radioanal. Nucl. Chem. 295(3), 1867.

Rotsch, D.A., Brown, M.A., Nolen, J.A., Brossard, T., Henning, W.F., Chemerisov, S.D., Gromov, R.G., Greene, J., 2018. Electron linear accelerator production and purification of scandium-47from titanium dioxide target. Appl. Radiat. Isot. 131, 77.

Severin, G.W., Engle, J.W., Valdovinos, H.F., Barnhart, T.E., Nickels, R.J., 2012. Cyclotron Produced ${ }^{44 g}$ Sc from Natural Calcium. Appl. Radiat. Isot. 70, 1526.

Singh, A., Baum, R., Klette, I., van der Meulen, N., Müller, C., Türler, A. Schibli, R., 2015. Scandium-44 DOTATOC PET/CT: first in-human molecular imaging of neuroendocrine tumors and possible perspectives for theranostics. J. Nucl. Med. 56, S3, 267.

Soppera, N., Dupont, E., Bossant, M., 2012. JANIS Book of proton-induced cross-sections. OECD NEA Data Bank.

Spellerberg, S., Scholten, B., Spahn, I., Bolten, W., Holzgreve, M., Coenen, H.H., Quaim, S.M., 2015. Target development for diversified irradiations at a medical cyclotron. Appl. Radiat. Isot. 104, 106.

Stolarz, A., Kowalska, J.A., Jastrzębski, J., Choiński, J., Sitarz, M., Szkliniarz, K., Trzcińska, A., Zipper, W., 2018. Targets for production of the medical radioisotopes with alpha and proton or deuteron beams. AIP Conference Proceedings 1962, 020004

Sura, J., Wejchert, Cz., Kuliński, S., Getka, S., 1982. Cyklotron C30 do produkcji krótkożyciowych izotopów dla zastosowań medycznych i przemysłowych. A. Sołtan Institute for Nuclear Studies (currently: National Centre for Nuclear Research) 1982/ZDAJ/PL/B internal report. 
Szkliniarz, K., 2016. Cyclotron production and research of radioisotopes for diagnostic and medical therapy. PhD Thesis (in polish). University of Silesia. Katowice.

Szkliniarz, K., Jastrzębski, J., Bilewicz, A., Chajduk, E., Choiński, J., Jakubowski, A., Janiszewska, Ł., Leszczuk, E., Łyczko, M., Sitarz, M., Stolarz, A., Trzcińska, A., Wąs, B., Zipper, W., 2015. Medical Radioisotopes Produced Using the Alpha Particle Beam from the Warsaw Heavy Ion Cyclotron. Acta Phys. Pol. A. 127, 1471.

Szkliniarz, K., Sitarz, M., Walczak, R., Jastrzębski, J., Bilewicz, A., Choiński, J., Jakubowski, A., Majkowska, A., Stolarz, A., Trzcińska, A., Zipper, W., 2016. Production of medical Sc radioisotopes with an alpha particle beam. Appl. Radiat. Isot. 118, 182.

Thirlof, P.G., Lang, C., Parodi, K., 2015. Perspectives for Highly-Sensitive PETBased Medical Imaging Using $\beta+\gamma$ Coincidences. Acta Phys. Pol. A 127, 1441.

Valdovinos, H.F., 2017. priv.com.

Valdovinos, H.F., Hernandez, R., Barnhart, T.E., Graves, S., Cai, W., Nickles, R.J., 2015. Separation of cyclotron-produced ${ }^{44} \mathrm{Sc}$ from a natural calcium target using a dipentylpentylphosphonate functionalized extraction resin. Appl. Radiat. Isot. 95, 23.

van der Meulen, N.P., Bunka, M., Domnanich, K.A., Müller, C., Haller, S., Vermeulen, C., Türler, A., Schibli, R., 2015. Cyclotron production of ${ }^{44}$ Sc: From bench to bedside. Nucl. Med. Biol. 42, 745.

Walczak, R., Krajewski, S., Szkliniarz, K., Sitarz, M., Abbas, K., Choński, J., Jakubowski, A., Jastrzębski, J., Majkowska, A., Simonelli, F., Stolarz, A., Trzcińska, A., Zipper, W., Bilewicz, A., 2015. Cyclotron production of ${ }^{43}$ Sc for PET imaging. Eur. J. Nucl. Med. Mol. Imaging Physics 2:33.

Ziegler, J.F., Ziegler, M.D., Biersack, J.P., 2008. SRIM code, version 2008.04, http://www.srim.org/ 


\section{TABLES}

\section{Table 1}

Isotopic composition of calcium carbonate targets made of natural and isotopically enriched materials. (The isotopes with the quoted enrichment values are available from ISOFLEX, USA).

\begin{tabular}{ccccccc}
\hline & ${ }^{40} \mathbf{C a}[\%]$ & ${ }^{42} \mathbf{C a}[\%]$ & ${ }^{43} \mathbf{C a}[\%]$ & ${ }^{44} \mathbf{C a}[\%]$ & ${ }^{46} \mathbf{C a}[\%]$ & ${ }^{48} \mathbf{C a}[\%]$ \\
\hline${ }^{n a t} \mathbf{C a}^{*}$ & 96.94 & 0.647 & 0.135 & 2.086 & 0.004 & 0.187 \\
\hline${ }^{42} \mathbf{C a} *$ & 29.9 & 68 & 0.4 & 1.5 & $<0.01$ & 0.2 \\
\hline${ }^{42} \mathbf{C a}$ & 3.24 & 95.9 & 0.13 & 0.7 & $<0.01$ & 0.03 \\
\hline${ }^{43} \mathbf{C a}^{*}$ & 23.8 & 1.0 & 62.2 & 12.8 & $<0.01$ & 0.2 \\
\hline${ }^{43} \mathbf{C a}$ & 5.3 & 0.18 & 90 & 4.44 & $<0.01$ & 0.08 \\
\hline${ }^{44} \mathbf{C a}^{*}$ & 5.03 & 0.1 & $<0.01$ & 94.8 & $<0.01$ & $<0.05$ \\
\hline${ }^{48} \mathbf{C a}^{*}$ & 27.9 & 0.3 & 0.1 & 2.2 & $<0.1$ & 69.2 \\
\hline${ }^{48} \mathbf{C a}$ & 2.72 & 0.02 & 0.01 & 0.15 & $<0.01$ & 97.1 \\
\hline
\end{tabular}

*Used in the experiments.

\section{Table 2}

Isotopic composition of the titanium dioxide target made of isotopically enriched material.

\begin{tabular}{cccccc}
\hline & ${ }^{46} \mathrm{Ti}[\%]$ & ${ }^{47} \mathrm{Ti}[\%]$ & ${ }^{48} \mathrm{Ti}[\%]$ & ${ }^{49} \mathrm{Ti}[\%]$ & ${ }^{50} \mathrm{Ti}[\%]$ \\
\hline${ }^{48} \mathrm{Ti}$ & 0.09 & 0.1 & $99.63(10)$ & 0.12 & 0.06 \\
\hline
\end{tabular}


Table 3

Comparison of the measured Thick Target Yield $[\mathrm{MBq} / \mu \mathrm{Ah}]$ of the medical Sc radioisotopes for the different $\mathrm{CaCO}_{3}$ targets irradiated with proton beams with various energies.

\begin{tabular}{|c|c|c|c|c|c|}
\hline Isotope: & ${ }^{43} \mathrm{Sc}$ & & Sc & ${ }^{44 m} \mathrm{Sc}$ & ${ }^{47} \mathrm{Sc}$ \\
\hline $\begin{array}{l}\text { Target and } \\
\text { enrichment: }\end{array}$ & $\begin{array}{c}{ }^{43} \mathrm{CaCO}_{3} \\
(90 \%) \\
\end{array}$ & ${ }^{\text {nat }} \mathrm{CaCO}_{3}$ & $\begin{array}{l}{ }^{44} \mathrm{CaCO}_{3} \\
(94.8 \%) \\
\end{array}$ & $\begin{array}{l}{ }^{44} \mathrm{CaCO}_{3} \\
(94.8 \%) \\
\end{array}$ & $\begin{array}{l}{ }^{48} \mathrm{CaCO}_{3} \\
(97.1 \%) \\
\end{array}$ \\
\hline $\begin{array}{l}\text { p energy } \\
{[\mathrm{MeV}]}\end{array}$ & & Thick t & rget yield [1] & $\mathrm{Bq} / \boldsymbol{\mu A h}]$ & \\
\hline 7.6 & $61(6)$ & $2.6(4)$ & $120(20)$ & $0.13(5)$ & \\
\hline 9.7 & 109(11) & $6.1(4)$ & $280(20)$ & $0.40(4)$ & $0.47(5)$ \\
\hline 10.7 & $180(20)$ & $8.2(9)$ & $370(40)$ & $0.84(5)$ & $2.1(2)$ \\
\hline 11.3 & & 8.7(9) & $400(40)$ & $1.5(1)$ & \\
\hline 11.9 & $200(20)$ & 11(1) & $500(50)$ & $1.3(2)$ & $6.8(8)$ \\
\hline 12.8 & $210(20)$ & $11(1)$ & $490(50)$ & $2.0(2)$ & $10(1)$ \\
\hline 14.3 & $260(30)$ & $16(1)$ & $730(50)$ & $2.7(3)$ & $21(2)$ \\
\hline 15.2 & $317(14)$ & $17.2(6)$ & $780(30)$ & $3.6(1)$ & $31(2)$ \\
\hline 17.5 & $410(40)$ & & & & \\
\hline 21.8 & & $23(1)$ & $1030(50)$ & $5.9(3)$ & $94(6)$ \\
\hline 22.0 & & $22(2)$ & $980(100)$ & $7.5(8)$ & \\
\hline 22.4 & & & & & $98(5)$ \\
\hline 22.8 & & $21(1)$ & $940(40)$ & $7.0(2)$ & $105(6)$ \\
\hline 28.2 & & & & & $136(8)$ \\
\hline 28.5 & & $23(1)$ & $1020(50)$ & $8.0(4)$ & 139(16) \\
\hline
\end{tabular}

Table 4.

Comparison of the measured Thick Target Yield $[\mathrm{MBq} / \mu \mathrm{Ah}]$ of the medical ${ }^{43} \mathrm{Sc}$ radioisotope irradiated with deuteron beams in two energy ranges.

\begin{tabular}{lc} 
Isotope: & ${ }^{43} \mathrm{Sc}$ \\
\hline $\begin{array}{l}\text { Target and } \\
\text { enrichment: }\end{array}$ & ${ }^{42} \mathrm{CaCO}_{3}$ \\
\hline d energy & TTY $)$ \\
[MeV] & {$[\mathbf{M B q} / \boldsymbol{\mu A h}]$} \\
\hline $4.7-0$ & $5.6(8)$ \\
$6.8-0$ & $45(4)$
\end{tabular}




\section{Table 5}

Examples of the deduced End of Beam intensities and relative impurities in medical Sc samples, produced with the available, most enriched (see Table 2) $\mathrm{CaCO}_{3}$ targets using proton and deuteron beams.

\begin{tabular}{|c|c|c|c|c|}
\hline & ${ }^{43} \mathrm{Sc}$ & & Sc & ${ }^{47} \mathrm{Sc}$ \\
\hline irradiation time & $4 \mathrm{~h}$ & & h & $8 \mathrm{~h}$ \\
\hline \multicolumn{5}{|c|}{ proton beam $(1 \mu \mathrm{A})$} \\
\hline \multirow{2}{*}{$\begin{array}{l}\text { energy }[\mathrm{MeV}] \\
\text { target }\end{array}$} & $15.2-2.2$ & $15.2-2.2$ & $15.2-2.2$ & $22.8-17.1$ \\
\hline & $\begin{array}{l}{ }^{43} \mathrm{CaCO}_{3} \\
(90 \%)\end{array}$ & ${ }^{\text {nat }} \mathrm{CaCO}_{3}$ & $\begin{array}{l}{ }^{44} \mathrm{CaCO}_{3} \\
(94.8 \%)\end{array}$ & $\begin{array}{l}{ }^{48} \mathrm{CaCO}_{3} \\
(97.1 \%)\end{array}$ \\
\hline EOB [MBq] & $910(40)$ & $50(2)$ & $2240(80)$ & $420(40)$ \\
\hline \multirow{7}{*}{$\begin{array}{ll} & { }^{43} \mathrm{Sc} \\
& { }^{44} \mathrm{Sc} \\
\text { relative } & { }^{44 m} \mathrm{Sc} \\
\text { intensity } & { }^{47} \mathrm{Sc} \\
\text { at EOB } & { }^{48} \mathrm{Sc} \\
& { }^{47} \mathrm{Ca} \\
& { }^{43} \mathrm{~K}\end{array}$} & 100 & $3.0(2)$ & $0.0049(6)$ & $0.25(4)$ \\
\hline & $12.0(1.5)$ & 100 & 100 & $0.106(13)$ \\
\hline & $0.95(12)$ & $0.62(3)$ & $0.62(3)$ & $0.0077(9)$ \\
\hline & $0.0131(17)$ & $0.56(7)$ & $0.0033(4)$ & 100 \\
\hline & $0.025(3)$ & $1.1(1)$ & $0.0063(8)$ & $26(3)$ \\
\hline & $0.00033(5)$ & $0.014(2)$ & 8.4(12)E-5 & $13.0(1.6)$ \\
\hline & & & & $0.0096(13)$ \\
\hline \multicolumn{5}{|c|}{ deuteron beam $(1 \mu \mathrm{A})$} \\
\hline \multirow{2}{*}{$\begin{array}{l}\text { energy [MeV] } \\
\text { target }\end{array}$} & $6.8-0$ & & & \\
\hline & $\begin{array}{l}{ }^{42} \mathrm{CaCO}_{3} \\
(95.9 \%)\end{array}$ & & & \\
\hline EOB [MBq] & 129(11) & & & \\
\hline \multirow{5}{*}{$\begin{array}{l}\text { relative } \\
\text { intensity } \\
\text { at EOB }\end{array}$} & 100 & & & \\
\hline & $0.25(16)$ & & & \\
\hline & $0.0054(19)$ & & & \\
\hline & $0.0019(2)$ & & & \\
\hline & $0.06(2)$ & & & \\
\hline
\end{tabular}




\section{Table 6}

${ }^{47} \mathrm{Sc}$ production results extrapolated for $8 \mathrm{~h}$ irradiation time with $1 \mu \mathrm{A}$ of proton beam and a ${ }^{48} \mathrm{TiO}_{2}$ (99.63\%) target for proton energy 28.0-18.3 MeV.

\begin{tabular}{|c|c|c|c|}
\hline \multicolumn{2}{|c|}{ projectile energy } & \multicolumn{2}{|c|}{ 28.0-18.3 MeV } \\
\hline \multicolumn{2}{|c|}{$\begin{array}{c}{ }^{47} \mathrm{Sc} \mathrm{TY} \\
{[\mathrm{MBq} / \boldsymbol{\mu A h}]}\end{array}$} & \multicolumn{2}{|c|}{$2.6(5)$} \\
\hline \multicolumn{2}{|c|}{ measuring time } & at EOB & $\begin{array}{l}40 \text { h post- } \\
\text { EOB }\end{array}$ \\
\hline \multicolumn{2}{|c|}{$\begin{array}{c}\text { activity }{ }^{47} \text { Sc } \\
{[\mathrm{MBq}]}\end{array}$} & $20(4)$ & $14(3)$ \\
\hline \multirow{7}{*}{$\begin{array}{c}\text { relative } \\
\text { isotopic } \\
\text { activities }\end{array}$} & ${ }^{47} \mathrm{Sc}$ & 100 & 100 \\
\hline & ${ }^{43} \mathrm{Sc}$ & $4.3(1.2)$ & $0.0048(14)$ \\
\hline & ${ }^{44 \mathrm{~g}} \mathrm{Sc}$ & $170(40)$ & 71(19) \\
\hline & ${ }^{44 m} \mathrm{Sc}$ & $80(20)$ & $66(18)$ \\
\hline & ${ }^{46} \mathrm{Sc}$ & $0.033(9)$ & $0.046(12)$ \\
\hline & ${ }^{48} \mathrm{Sc}$ & $0.08(2)$ & $0.058(15)$ \\
\hline & ${ }^{48} \mathbf{V}$ & 190(50) & $250(60)$ \\
\hline
\end{tabular}




\section{FIGURES}

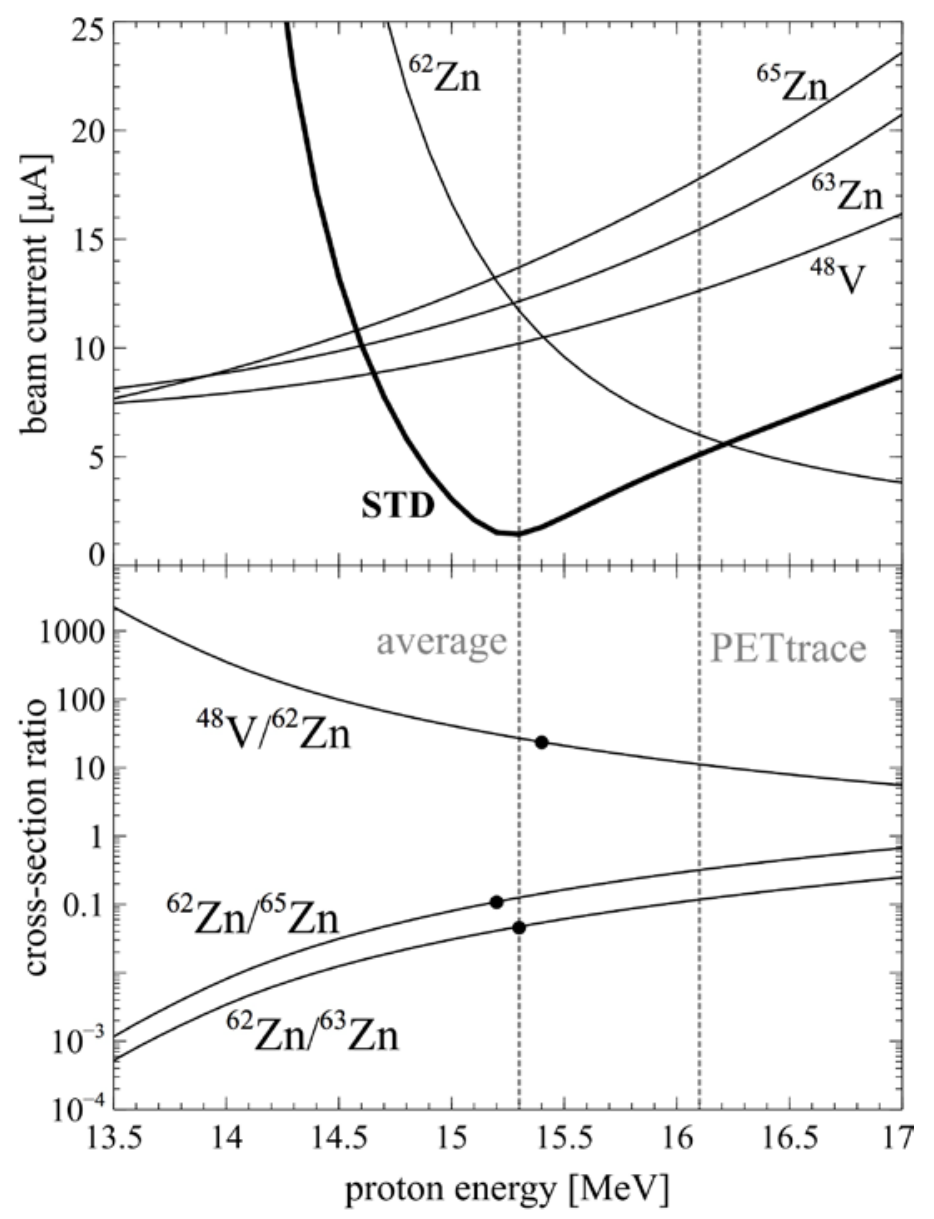

Fig. 1. Upper part: the proton beam current irradiating samples in the external PETtrace beam line as a function of the bombarding energy calculated using the monitor reaction cross sections as recommended in (IAEA 2017). The standard deviation between calculated current values is also presented. Lower part: comparison of the saturation activity ratio for monitor reactions sensitive to the beam energy values. The assessed proton beam energy is $15.3+-0.1 \mathrm{MeV}$ in the middle of the monitor foils. 


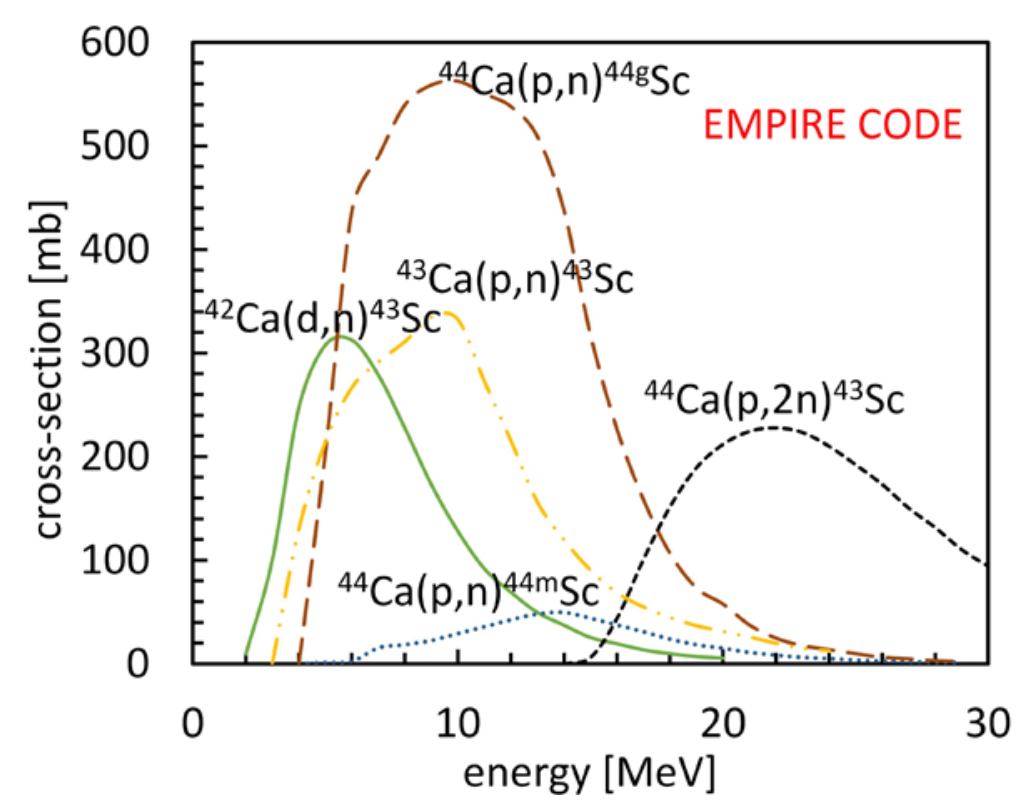

Fig. 2. Calculated cross-sections for the production of ${ }^{43} \mathrm{Sc}$ and ${ }^{44} \mathrm{Sc}$ radioisotopes with proton and deuteron projectiles. The EMPIRE (Herman et al., 2007) evaporation code was employed.

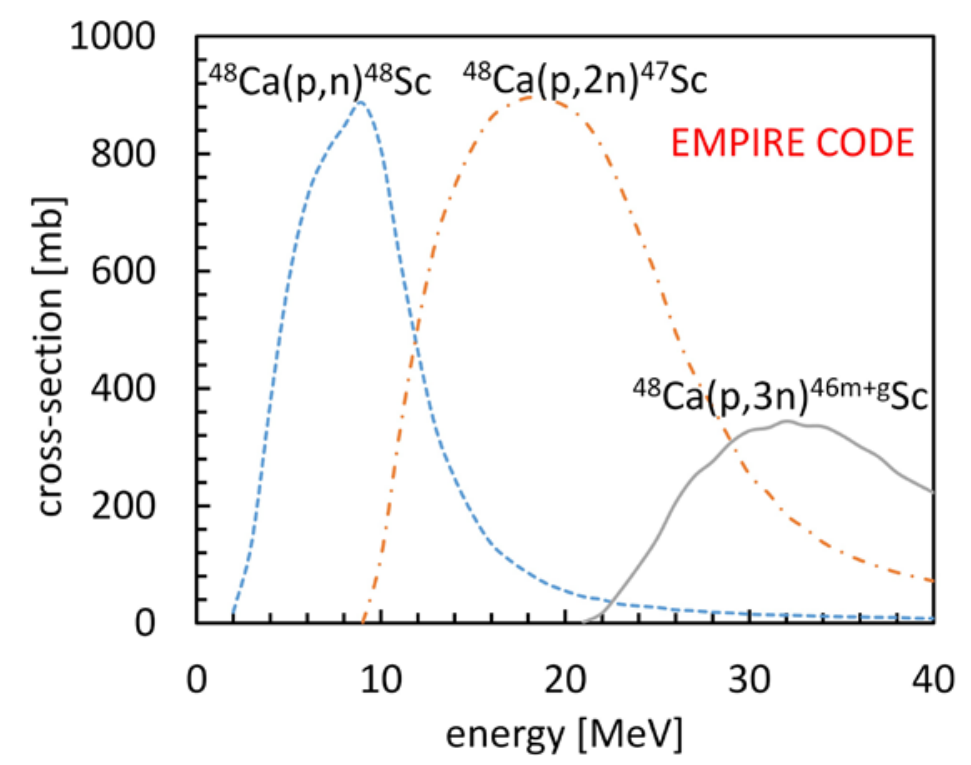

Fig. 3. Calculated cross-sections for proton induced reactions with the emission of 1, 2 and 3 neutrons on a ${ }^{48} \mathrm{Ca}$ target. The EMPIRE (Herman et al., 2007) evaporation code was employed. 


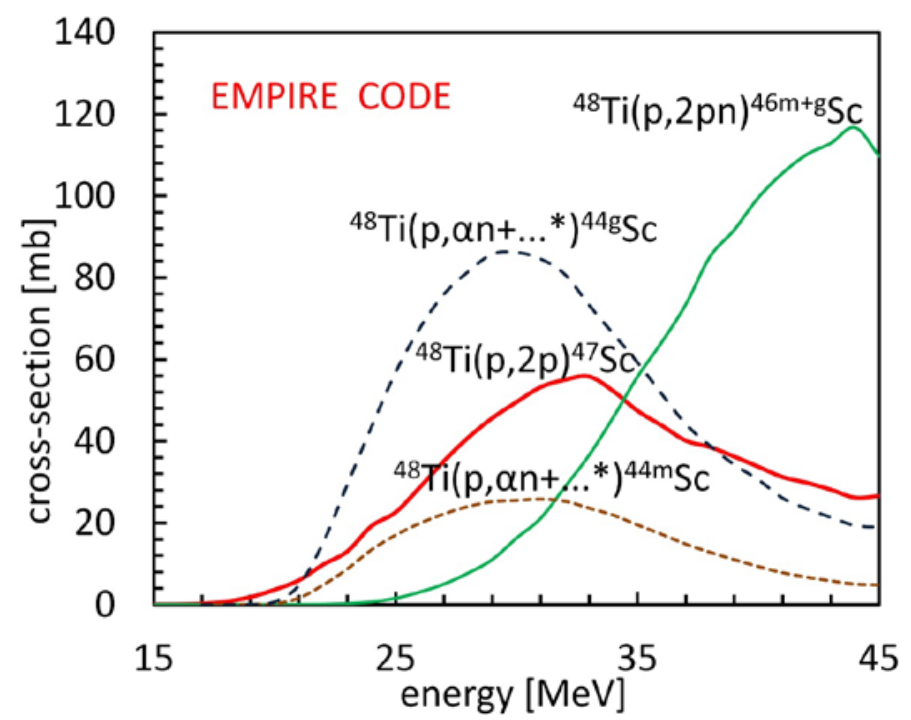

Fig. 4. Calculated cross-sections for the production of ${ }^{47} \mathrm{Sc},{ }^{46} \mathrm{Sc}$ and ${ }^{44} \mathrm{Sc}$ radioisotopes with proton beams on ${ }^{48} \mathrm{Ti}$ target. The EMPIRE (Herman et al., 2007) evaporation code was employed. The symbol * indicates other reaction channels considered: $(p, \alpha+n)+(p, d+t)+(p, n+p+t)+\left(p, 2 n+{ }^{3} H e\right)+(p, n+2 d)+$ $(p, 2 n+p+d)+(p, 3 n+2 p)$.

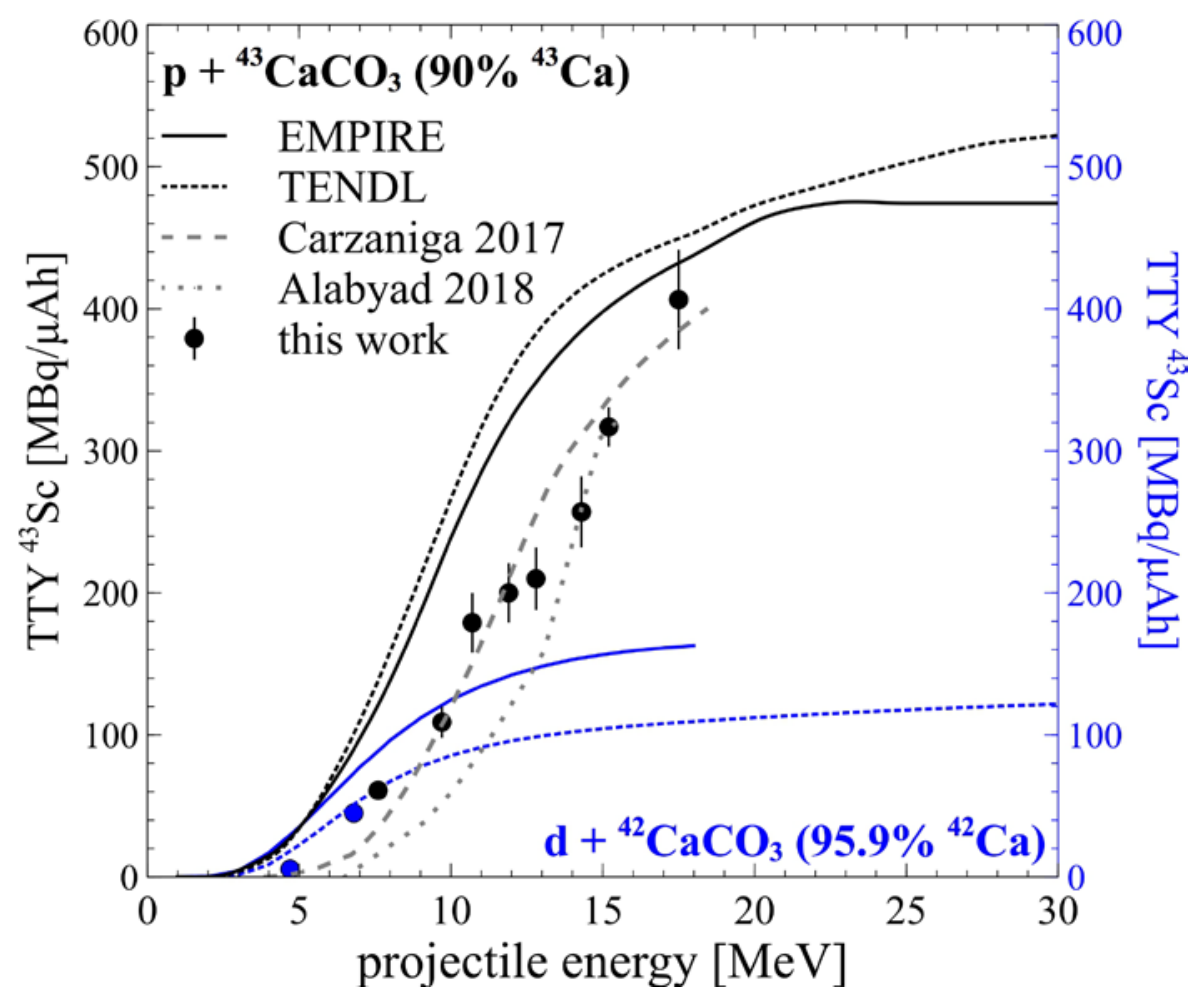

Fig. 5. Comparison of the experimentally determined ${ }^{43} \mathrm{Sc}$ Thick Target Yield with the theoretical estimates for a deuteron beam impinging on an isotopically enriched ${ }^{42} \mathrm{CaCO}_{3}$ target and protons impinging on enriched ${ }^{43} \mathrm{CaCO}_{3}$ (experimental data are recalculated for $95.9 \%$ target enrichment for deuterons and 
90\% for protons). TENDL data are taken from (Koning and Rochman, 2012) while EMPIRE from (Herman et al., 2007).

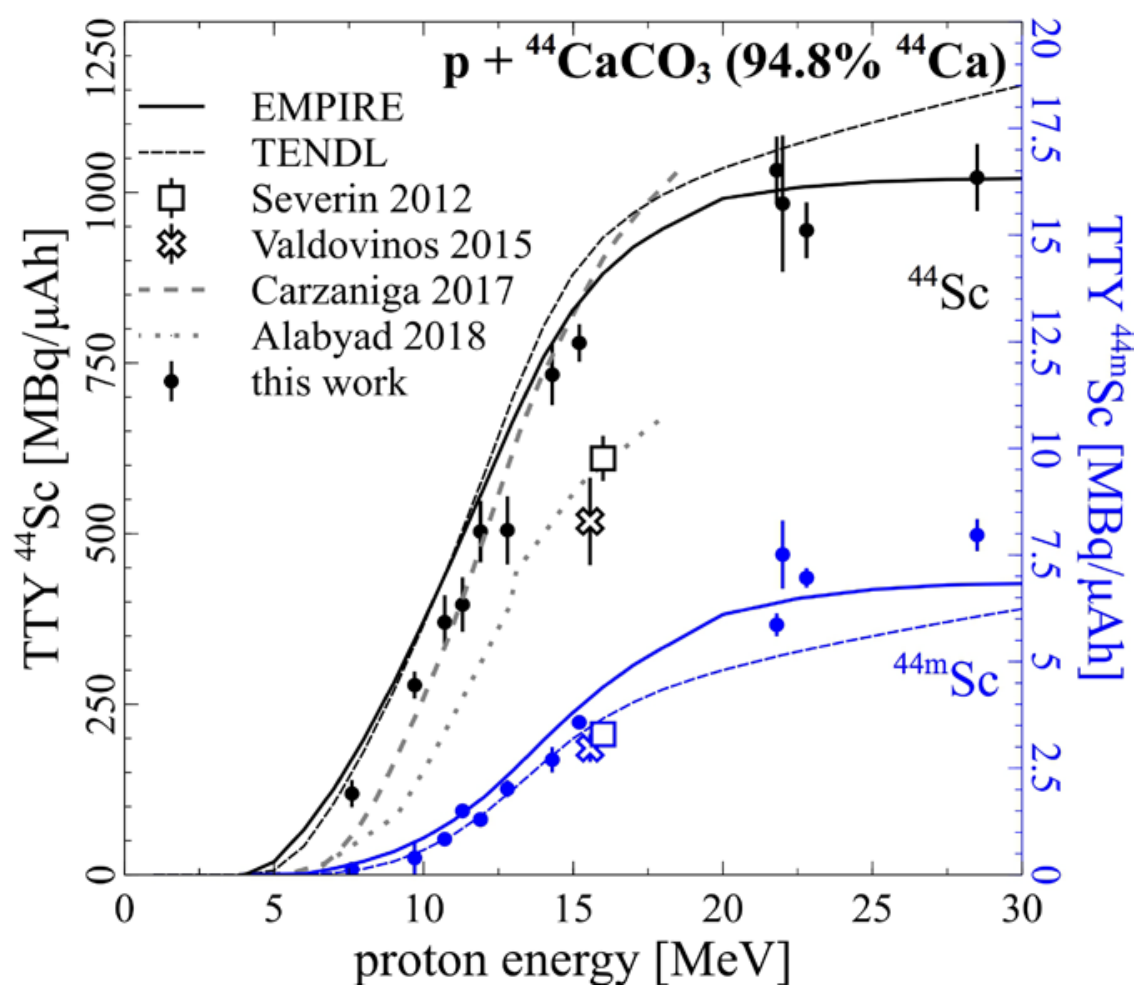

Fig. 6. Measured Thick Target Yields of ${ }^{44 \mathrm{~g}} \mathrm{Sc}$ and ${ }^{44 \mathrm{~m}} \mathrm{Sc}$ radioisotopes produced in the ${ }^{44} \mathrm{Ca}(\mathrm{p}, \mathrm{n})$ reaction compared with the theoretical predictions based on TENDL cross-section and EMPIRE evaporation code calculations. The data from Refs. (Severin et al., 2012) and (Valdovinos et al., 2015) measured with a metallic target and converted to the ${ }^{44} \mathrm{CaCO}_{3}$ equivalents are also shown. Additional TTY curves are calculated from cross-section data measured by (Carzianga et al., 2017) and (Alabyad et al., 2018). 


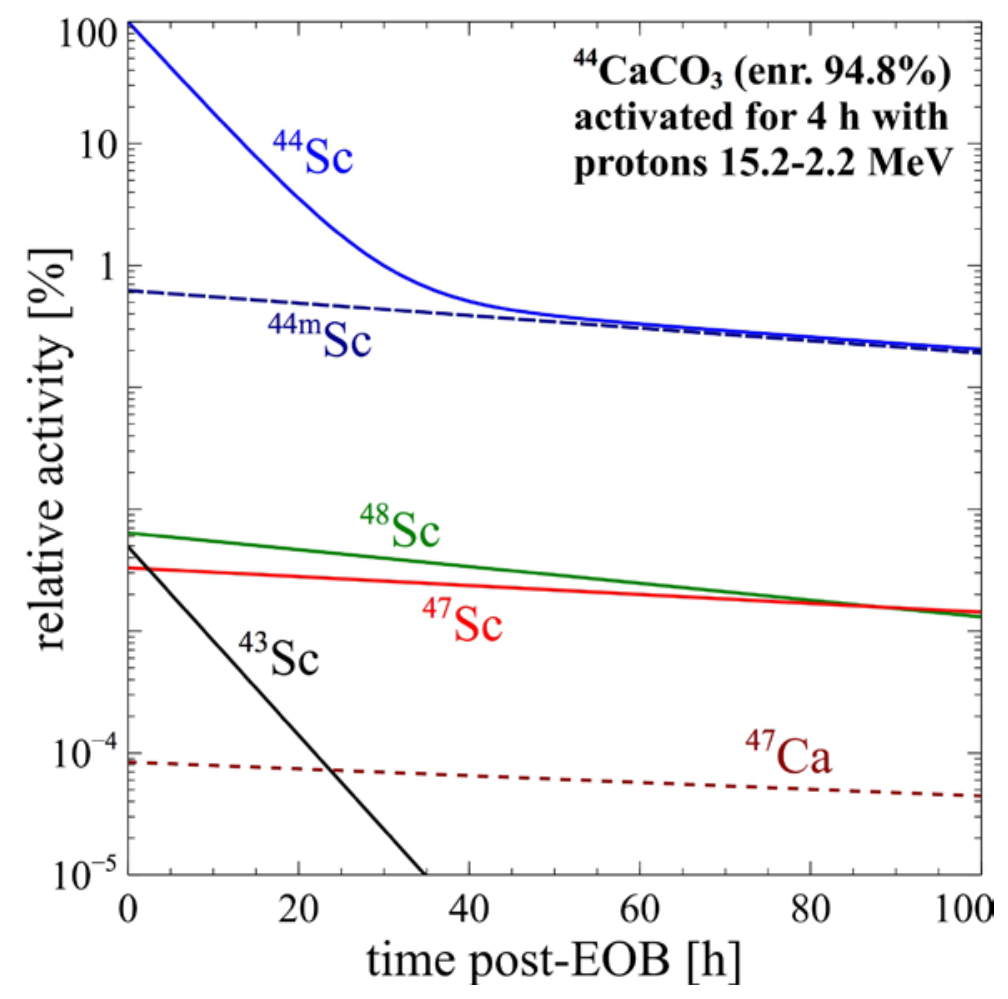

Fig. 7. Evolution with time of the relative intensities of Sc radioisotopes produced during a $4 \mathrm{~h}$ irradiation of a ${ }^{44} \mathrm{CaCO}_{3}(94.8 \%)$ target with a $15.2-2.2 \mathrm{MeV}$ proton beam.

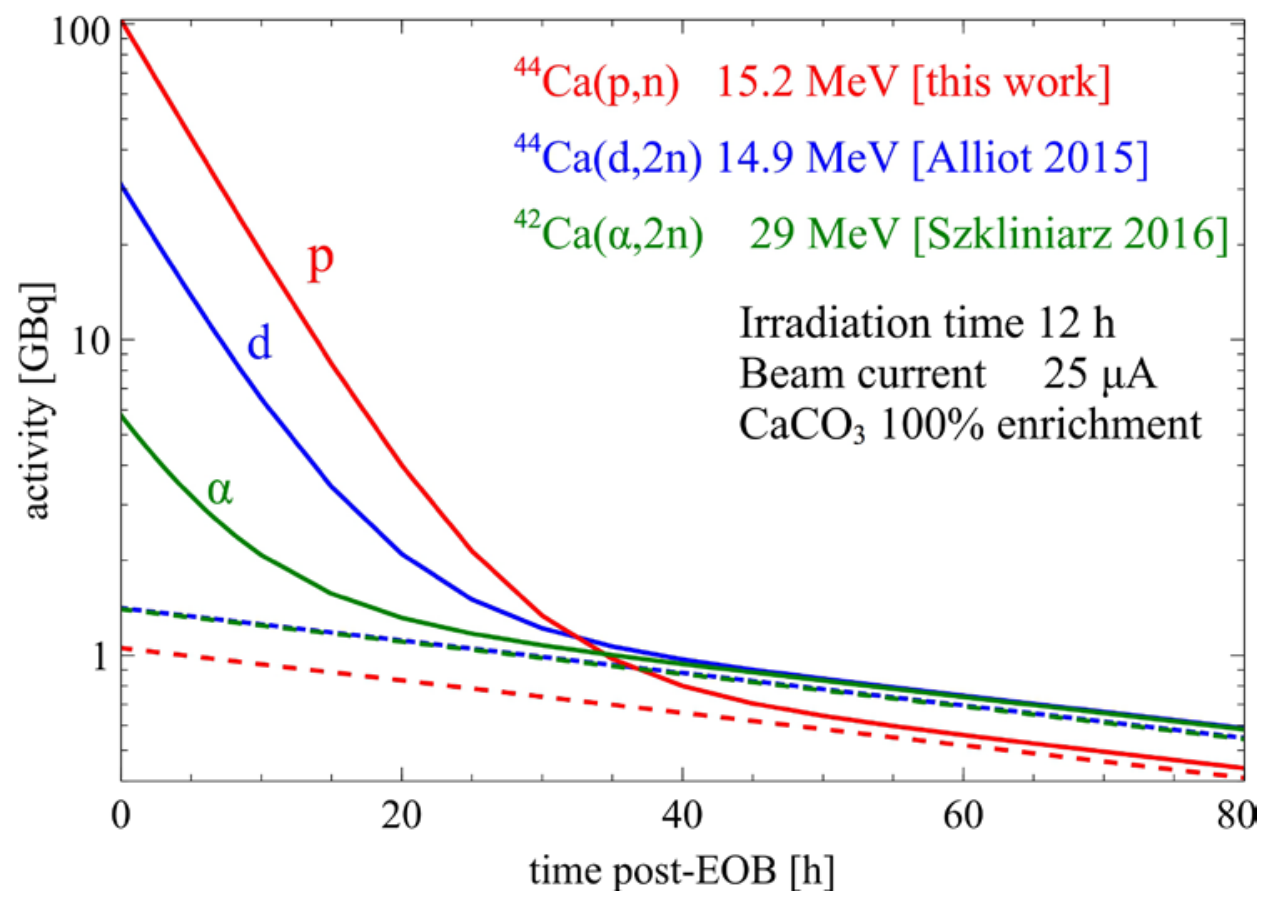

Fig. 8. Activity of produced samples of ${ }^{44 \mathrm{~m}, \mathrm{~g}} \mathrm{Sc}$ after $12 \mathrm{~h}$ irradiation time of a thick target with proton, deuteron and alpha particle beams of $25 \mu \mathrm{A}$ intensity. 


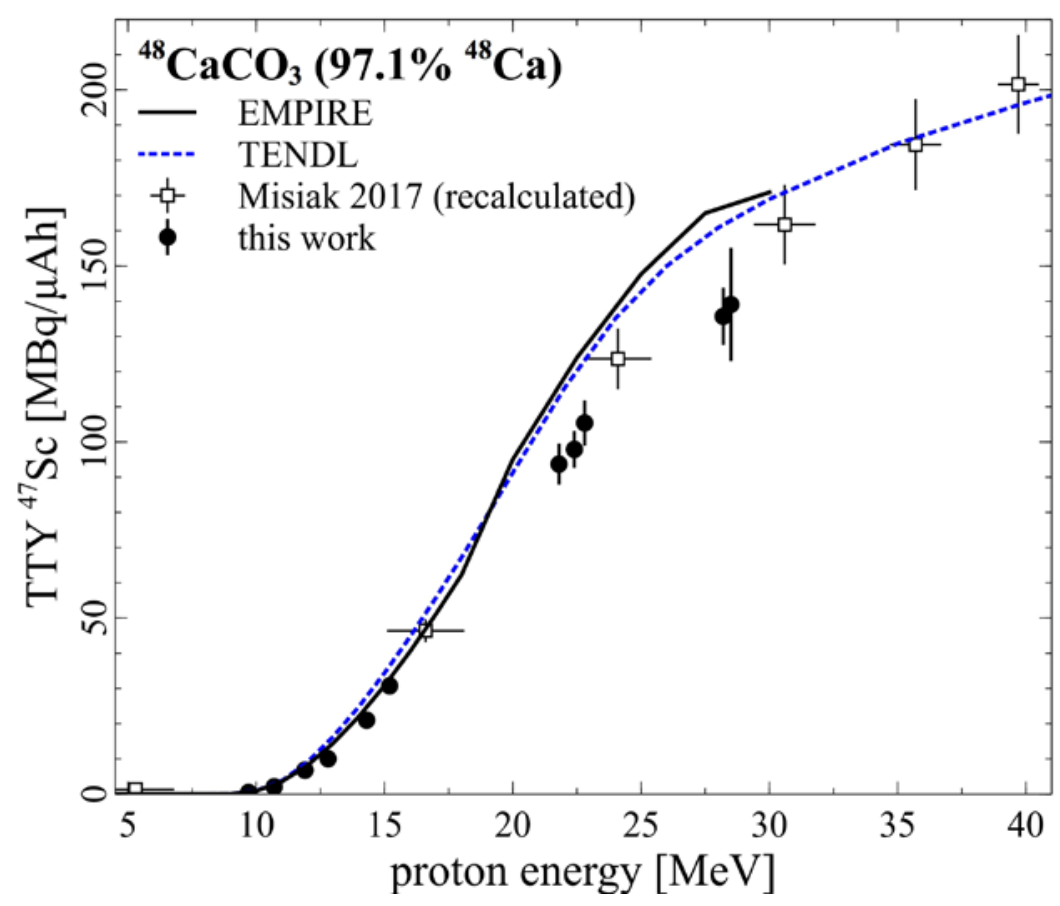

Fig. 9. Measured Thick Target Yield of ${ }^{47} \mathrm{Sc}$ obtained using the ${ }^{48} \mathrm{Ca}(\mathrm{p}, 2 \mathrm{n})$ reaction with theoretical predictions based on EMPIRE (Herman et al., 2007) evaporation code calculations and TENDL (Koning and Rochman, 2012) predictions. The experimental data are converted to $97.1 \%{ }^{48} \mathrm{CaCO}_{3}$ target enrichment. The data of Ref. (Misiak et al., 2017) are obtained from their partial yields in the measured energy intervals adding the interpolated, not measured values.

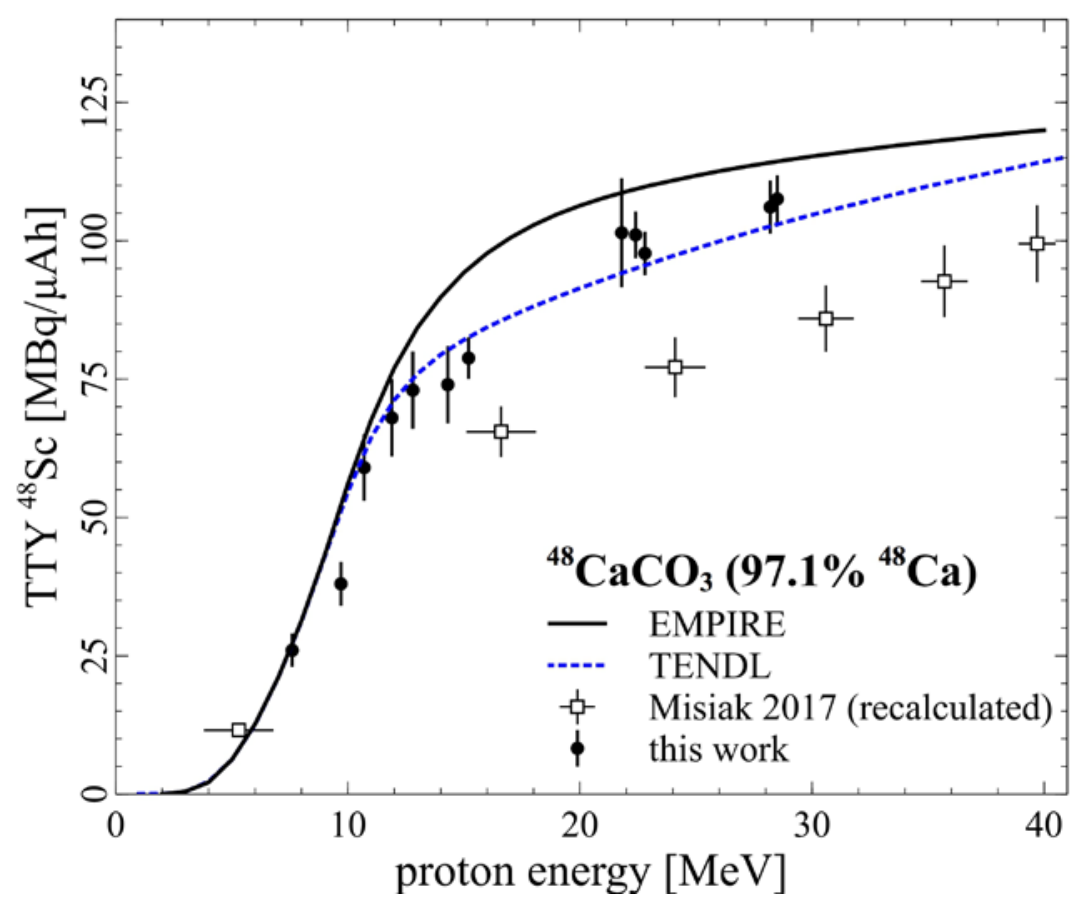

Fig. 10. The same as Fig. 8 but for the ${ }^{48} \mathrm{Ca}(p, n){ }^{48} \mathrm{Sc}$ reaction. 


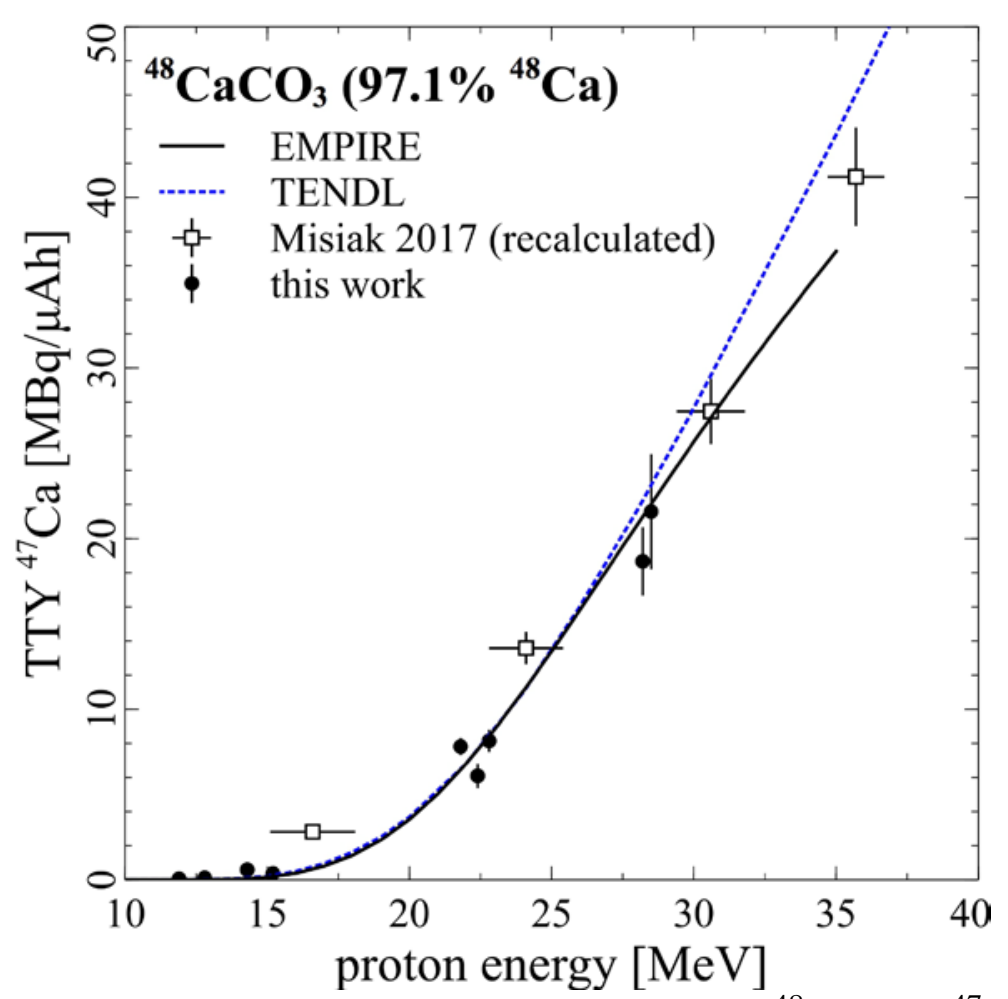

Fig. 11. The same as Fig. 8 but for the ${ }^{48} \mathrm{Ca}(\mathrm{p}, \mathrm{x})^{47} \mathrm{Ca}$ reaction.

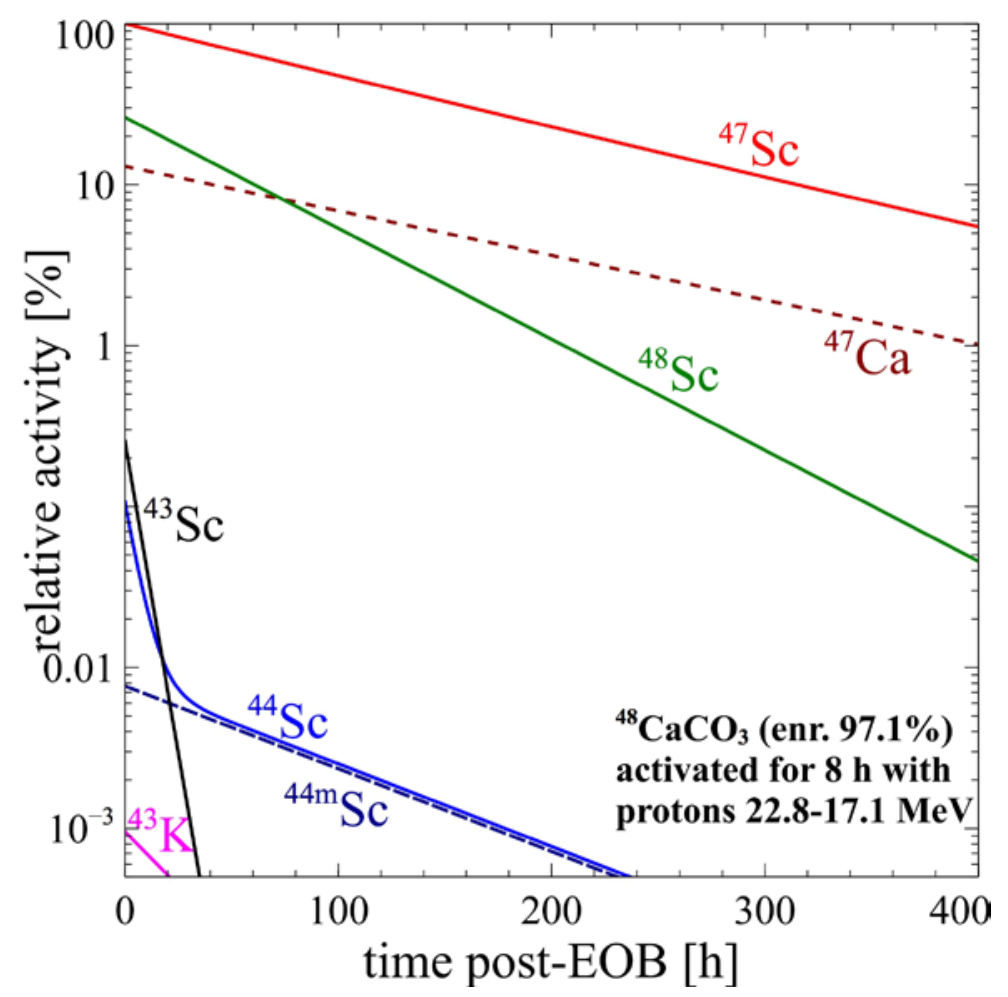


Fig. 12. Evolution with time of the relative intensities of radioisotopes produced on Ca during an $8 \mathrm{~h}$ irradiation of a ${ }^{48} \mathrm{CaCO}_{3}$ target with a 22.8-17.1 MeV proton beam. The experimental data are converted to $97.1 \%{ }^{48} \mathrm{CaCO}_{3}$ target enrichment. 